\title{
Outer Hair Cell Glutamate Signaling through Type II Spiral Ganglion Afferents Activates Neurons in the Cochlear Nucleus in Response to Nondamaging Sounds
}

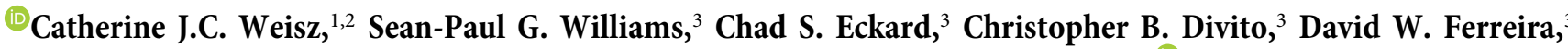 \\ Kristen N. Fantetti, ${ }^{1,3}$ Shenin A. Dettwyler, ${ }^{3}$ Hou-Ming Cai, ${ }^{1,3}$ Maria E. Rubio, ${ }^{1,3 *}{ }^{\circ}$ Karl Kandler, ${ }^{1,3}$ and \\ ${ }^{-1}$ Rebecca P. Seal ${ }^{1,3 *}$ \\ ${ }^{1}$ Department of Otolaryngology, University of Pittsburgh School of Medicine, Pittsburgh, Pennsylvania $15260,{ }^{2}$ Section on Neuronal Circuitry, \\ National Institute for Deafness and other Communication Disorders, National Institutes of Health, Bethesda, MD 20892, and ${ }^{3}$ Department of \\ Neurobiology, University of Pittsburgh School of Medicine, Pittsburgh, Pennsylvania 15260
}

Cochlear outer hair cells (OHCs) are known to uniquely participate in auditory processing through their electromotility, and like inner hair cells, are also capable of releasing vesicular glutamate onto spiral ganglion (SG) neurons: in this case, onto the sparse Type II SG neurons. However, unlike glutamate signaling at the inner hair cell-Type I SG neuron synapse, which is robust across a wide spectrum of sound intensities, glutamate signaling at the OHC-Type II SG neuron synapse is weaker and has been hypothesized to occur only at intense, possibly damaging sound levels. Here, we tested the ability of the OHC-Type II SG pathway to signal to the brain in response to moderate, nondamaging sound $(80 \mathrm{~dB}$ SPL) as well as to intense sound (115 dB SPL). First, we determined the VGluTs associated with OHC signaling and then confirmed the loss of glutamatergic synaptic transmission from OHCs to Type II SG neurons in KO mice using dendritic patch-clamp recordings. Next, we generated genetic mouse lines in which vesicular glutamate release occurs selectively from OHCs, and then assessed c-Fos expression in the cochlear nucleus in response to sound. From these analyses, we show, for the first time, that glutamatergic signaling at the OHC-Type II SG neuron synapse is capable of activating cochlear nucleus neurons, even at moderate sound levels.

Key words: cochlear nucleus; glutamate signaling; granule cells; outer hair cells; Type II spiral ganglion neurons

Significance Statement

Evidence suggests that cochlear outer hair cells (OHCs) release glutamate onto Type II spiral ganglion neurons only when exposed to loud sound, and that Type II neurons are activated by tissue damage. Knowing whether moderate level sound, without tissue damage, activates this pathway has functional implications for this fundamental auditory pathway. We first determined that OHCs rely largely on VGluT3 for synaptic glutamate release. We then used a genetically modified mouse line in which OHCs, but not inner hair cells, release vesicular glutamate to demonstrate that moderate sound exposure activates cochlear nucleus neurons via the OHC-Type II spiral ganglion pathway. Together, these data indicate that glutamate signaling at the OHC-Type II afferent synapse participates in auditory function at moderate sound levels.

\section{Introduction}

Cochlear inner hair cells (IHCs) are the principal auditory receptors, transforming mechanical sound information into glutamate-mediated synaptic signaling that activates centrally projecting Type I spiral ganglion neurons (SGNs) (Glowatzki and Fuchs, 2002). Glutamate packaging into IHC synaptic

colony; Linh Vong and Bradford Lowell for the Vglut $3^{\text {IRESCre }}$ mice; and Drs. Jian Zuo and Jie Fang for providing the Prestin ${ }^{\text {CreERT2 }}$ mice.

*M.E.R. and R.P.S. contributed equally to this work as senior authors.

The authors declare no competing financial interests.

C.J.C. Weisz' present address: Section on Neuronal Circuitry, National Institute for Deafness and other Communication Disorders, National Institutes of Health, Bethesda, MD 20892.

Correspondence should be addressed to Rebecca P. Seal at rpseal@pitt.edu or Catherine J.C. Weisz at catherine.weisz@nih.gov.

https://doi.org/10.1523/JNEUROSCI.0619-20.2021

Copyright $\odot 2021$ the authors 
vesicles relies on VGluT3, and mice lacking VGluT3 are deaf (Ruel et al., 2008; Seal et al., 2008; Kim et al., 2019). Outer hair cells (OHCs) lower the sound detection threshold and sharpen the basilar membrane tuning curve via their electromotility (Brownell et al., 1985; Evans and Dallos, 1993). However, OHCs also release vesicular glutamate (Weisz et al., 2009) that excites the less abundant Type II SGNs (5\%-10\% of SGNs) (Spoendlin, 1967, 1969; Kiang et al., 1982; Dannhof and Bruns, 1993; Hafidi, 1998), but the VGluT mediating OHC glutamate packaging is unclear (Seal et al., 2008).

IHC-Type I and OHC-Type II synapses exhibit distinct functional properties. IHCs use fast, synchronous release of hundreds to thousands of vesicles that are graded with sound intensity (Glowatzki and Fuchs, 2002; Nouvian et al., 2006), whereas OHCs contain orders of magnitude fewer vesicles (Dunn and Morest, 1975; Liberman et al., 1990; Weisz et al., 2012) and exhibit a much lower vesicle release probability (Weisz et al., 2012). The anatomic arrangement of Type I- and Type II-SGN synaptic contacts with hair cells also differs. Thick, myelinated Type I SGNs innervate a single IHC (Fekete et al., 1984; Ryugo et al., 1991), whereas thin, unmyelinated Type II SGNs innervate up to $\sim 30$ OHCs (Perkins and Morest, 1975; Ginzberg and Morest, 1983, 1984; Berglund and Ryugo, 1987; Brown, 1987; Simmons and Liberman, 1988a,b; Liberman et al., 1990; Echteler, 1992; Koundakjian et al., 2007; Weisz et al., 2012). Computational modeling suggests that integration of all OHC inputs, such as with loud or broadband sound, is required for suprathreshold Type II SGN activation (Weisz et al., 2014). In vivo recordings suggest that Type II SGNs are insensitive to even high intensity sound (Robertson, 1984; Brown, 1994; Robertson et al., 1999). More recently, ATP released by damaged OHCs (Weisz et al., 2009; Flores et al., 2015; Liu et al., 2015) and perhaps supporting cells (Muñoz et al., 2001) was shown to activate Type II SGN. It was subsequently postulated that Type II afferents mediate soundinduced nociception. It nevertheless remains unknown whether a lower-intensity natural stimulus, such as moderate sound, is sufficient to activate the OHC-Type II afferent pathway.

In the cochlear nucleus (CN), Type I afferents project broadly to both dorsal (DCN) and ventral cochlear nuclei (VCN). Type II afferents branch in the VCN alongside Type I SGN from the same cochlear region, but have a sparser projection, primarily to the granule cell domain (GCD) (Brown, 1987; Brown et al., 1988; Simmons and Liberman, 1988b; Brown and Ledwith, 1990; Ryugo et al., 1991; Morgan et al., 1994; Berglund et al., 1996; Hurd et al., 1999; Benson and Brown, 2004). The role of the GCD is unclear, but it may respond to information concerning head or pinna position, attention, sound localization, or sound recognition (Shore et al., 2000; Rubio, 2018) via auditory and nonauditory input (Itoh et al., 1987; Weinberg and Rustioni, 1987; Kevetter and Perachio, 1989; Pedemonte et al., 1990; Klepper and Herbert, 1991; Young et al., 1995; Wright and Ryugo, 1996; Davis and Young, 1997; Kanold and Young, 2001; Zhan et al., 2006; Barker et al., 2012).

In this study, we developed mouse models to test whether exposure of mice to moderate, nondamaging ( $80 \mathrm{~dB} \mathrm{SPL}$ ) sound can activate the OHC-Type II afferent-CN pathway. First, we determined which VGluT isoforms are expressed by OHCs. We then generated mouse lines in which vesicular glutamate release is isolated to either IHCs or OHCs to show that nondamaging sound levels activate CN neurons via OHC-Type II SGN glutamate signaling. Increasing the sound to a more intense level (115 dB SPL) activates additional large CN neurons, suggesting that Type II neurons may potentially encode sound intensity.
Table 1. Genetic mouse lines used in this study

\begin{tabular}{|c|c|c|c|}
\hline Genotype & Transgenic type & $\begin{array}{l}\text { Cre expression } \\
\mathrm{IHC} \text { and/or } \mathrm{OHC}\end{array}$ & Mouse reference \\
\hline Vglut $T^{\text {IRESCre }}$ & Knockin & Neither & Harris et al., 2014 \\
\hline Vglut2 $^{I R E S C r e}$ & Knockin & Neither & Vong et al., 2011 \\
\hline Vglut2 ${ }^{\text {Cre }}$ & $\mathrm{BAC}$ transgenic & $\mathrm{IHC}$ and $\mathrm{OHC}$ & Borgius et al., 2010 \\
\hline Vglut3 ${ }^{\text {IRESCre }}$ & Knockin & $\mathrm{IHC}$ and $\mathrm{OHC}$ & Cheng et al., 2017 \\
\hline Vglut $3^{\text {Cre }}$ & BAC transgenic & $\mathrm{OHC}$ & Grimes et al., 2011 \\
\hline Prestin ${ }^{\text {CreERT2 }}$ & Tamoxifen-dependent & $\mathrm{OHC}$ & Fang et al., 2012 \\
\hline Vglut $3^{f / f f l}$ & Conditional KO & NA & $\begin{array}{l}\text { Divito et al., 2015; } \\
\text { Peirs et al., } 2015\end{array}$ \\
\hline Vglut2 $2^{f / f l}$ & Conditional KO & NA & Tong et al., 2007 \\
\hline Vglut $^{-/-}$ & Global KO & NA & Seal et al., 2008; \\
\hline Ai14-tdTomato & Rosa locus & NA & Madisen et al., 2012 \\
\hline
\end{tabular}

Table 2. Crossed genetic mouse lines

\begin{tabular}{|c|c|}
\hline Mouse cross & Impact on cochlear hair cells \\
\hline 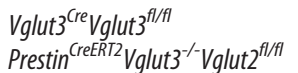 & $\begin{array}{l}\text { No } \mathrm{IHC} \text { glutamate release } \\
\text { No } \mathrm{IHC} \text { or } \mathrm{OHC} \text { glutamate release }\end{array}$ \\
\hline
\end{tabular}

Thus, this fundamental auditory pathway is able to participate in central auditory processing under nonpathologic conditions.

\section{Methods and Materials}

Animals. Animal use protocols were reviewed and approved by the University of Pittsburgh Institutional Animal Care and Use Committee. Animals were housed in micro-isolator cages on a standard $12 \mathrm{~h}$ sleep/wake cycle (7:00 A.M. lights on, 7:00 P.M. lights off) with ad libitum access to food and water. All efforts were made to minimize the number of animals used and to avoid pain or discomfort. Mice are described in Tables 1 and 2 . Prestin ${ }^{\text {CreERT2 }}, V$ Vlut $3^{\text {Cre }}, V_{\text {glut }} 3^{\text {flfll }}, V_{\text {glut }} 3^{-1-}$, and Vglut $2^{f l / f l}$ mice were on a mixed FVB/N and $\mathrm{C} 57 \mathrm{Bl} / 6 \mathrm{~J}$ background. Mice used to examine tdTomato expression and for ISH were on C57Bl/6J background. Mice of both sexes and ranging in age from postnatal day 7 (P7) to 3 months were used.

Tamoxifen injections. Tamoxifen (Sigma Millipore, \#T5648) was dissolved in ethanol at a concentration of 5 or $20 \mathrm{mg} / \mathrm{ml}$, added to a ratio of 1:1 corn oil, and ethanol evaporated away with a SpeedVac for $2-4 \mathrm{~h}$ at $37^{\circ} \mathrm{C}$. Dissolved tamoxifen was stored at $4^{\circ} \mathrm{C}$ in the dark for up to $5 \mathrm{~d}$. Pups were injected intraperitoneally with $40 \mathrm{mg} / \mathrm{kg}$ tamoxifen from P2 to P4 or $75 \mathrm{mg} / \mathrm{kg}$ tamoxifen from P21 to P25.

In situ hybridization (ISH) of cochleae. Mice (P8.5) were deeply anesthetized with isoflurane and decapitated after cervical dislocation. Cochleae were quickly removed, immersed in $4 \%$ PFA in $0.1 \mathrm{~m} \mathrm{PBS}, \mathrm{pH}$. 7.4, and postfixed overnight at $4^{\circ} \mathrm{C}$. Cochleae were then decalcified using 10\% EDTA in PBS, pH. 8.0, at room temperature for $3 \mathrm{~h}$. Tissue was cryo-protected in 30\% sucrose, embedded in OCT mounting medium, and cut with a cryostat (Microm HM550) (20 $\mu \mathrm{m}$ thickness) directly onto SuperFrost Plus slides (Fisherbrand; catalog \#12-550-15). RNAscope Multiplex Fluorescent Reagent Kit version 2 (catalog \#323110) was used to perform ISH with RNAscope probes according to the manufacturer's protocols recommended for fixed frozen tissue. Vglut3 probe (Mm-Slc17a8, catalog \#431261-C1) was visualized in Cy3, and Vglut1 (Mm-Slc17a7, catalog \#416631-C3) and Vglut2 (MmSlc17a6, catalog \#319171-C2) probes were visualized in Cy5 (cata$\log$ \#NEL744001KT-TSA Plus Cyanine 3 and NEL745001KT-TSA Plus Cyanine 5, Akoya Biosciences). Positive and negative control probes were tested on other sections simultaneously. Cells 
showing at least three puncta were considered positive. RNAscope Multiplex Fluorescent version 2 assay was combined with immunofluorescence according to the manufacturer's protocols on fixed tissues (Technical Note, 323100-TN, Advanced Cell Diagnostics) using the following primary antibody: Myosin VIIa raised in rabbit (1:500, Proteus Biosciences, catalog \#25-6790) and incubated in donkey anti-Rabbit AlexaFluor-488 (1:1000, Jackson ImmunoResearch Laboratories, 711-545-152). Samples were mounted with ProLong Gold Antifade Mountant with DAPI (Thermo Fisher Scientific, catalog \#P36931). Cochlea sections were imaged with a confocal laser-scanning microscope (Nikon A1R), Nikon Eclipse Ti2 microscope, and Nikon NIS-Elements software. Z-series were scanned at $40 \times$ magnification and a $z$ step of $2.0 \mu \mathrm{m}$.

Cochlear whole-mount immunofluorescence. Mice were anesthetized with isoflurane (100\%, Butler Schein), decapitated, and the cochlea isolated and perfused through the round window with $1 \mathrm{ml}$ of $4 \%$ PFA in PBS, postfixed for $2 \mathrm{~h}$ in $4 \%$ PFA on ice, and rinsed by perfusing the round window with $1 \mathrm{ml}$ PBS. The organ of Corti was micro-dissected into individual turns as a whole-mount preparation and stained as described previously (Akil et al., 2006, 2012; Seal et al., 2008). Tissue was incubated in blocking solution ( $5 \%$ donkey serum, $0.25 \%$ Triton X-100 in PBS) for $1 \mathrm{~h}$ at room temperature. The following primary antibodies were added to blocking solution and incubated overnight at $4^{\circ} \mathrm{C}$ : rabbit anti-MyoVI (1:100, Proteus Biosciences, catalog \#25-6791) or guinea pig anti-VGluT3 (1:2500, gift from Robert Edwards, University of California at San Francisco). Following PBS rinses, secondary antibodies conjugated to AlexaFluor dyes (1:1000, Jackson ImmunoResearch Laboratories) were diluted in blocking solution, and tissue was incubated for $2 \mathrm{~h}$ at room temperature. In some experiments, AlexaFluor-555 or -647 Phalloidin stain (Thermo Fisher Scientific) was added to the secondary antibody incubation step. Following PBS rinses, explants were mounted on glass slides in Fluoromount G (Southern Biotechnology, \#0100), coverslipped, and imaged with a confocal microscope (Nikon Eclipse FN1 or Carl Zeiss LSM 780). Confocal image stacks were captured with a $20 \times, 40 \times$, or $63 \times$ objective, collapsed into $2 \mathrm{D}$ maximum intensity projections, and analyzed using National Institutes of Health ImageJ software.

Noise exposure/acoustic startle response. Sound stimuli were delivered using the Kinder Startle Monitor System SM100 (Kinder Scientific). Mice were placed into a darkened sounddampening chamber and remained within a restraining device that prevents the animal from turning around during testing. Calibration was performed using a sound level meter microphone placed in the position of the animal. For noise exposure experiments, mice were acclimatized to the chamber for $15 \mathrm{~min}$ without noise stimulus and then exposed to a constant 80 or $115 \mathrm{~dB}$ broadband noise $(3-30 \mathrm{kHz})$ for $1 \mathrm{~h}$. For acoustic startle testing, mice were acclimatized to the chamber by presentation of a constant $60 \mathrm{~dB}$ white noise for $5 \mathrm{~min}$ and then randomly exposed to $400 \mathrm{~ms}$ bursts of broadband noise (3-30 kHz) at pseudorandomized intensity levels (60-120 dB SPL) with 15-25 s gaps between bursts.

Auditory brainstem responses (ABRs). ABRs to click and pure tones were measured before and 2 weeks after noise exposure using a Tucker-Davis Technologies evoked potential workstation (RZ6-A-P1) and a close-field speaker (MF1-M, Tucker-Davis Technologies) following the protocol described by Clarkson et al. (2016). Three subcutaneous needle electrodes were connected to a 4-channel low-impedance headstage (RA4 LI, Tucker-Davis Technologies). Sound stimuli signals were generated and analyzed using BioSigRZ software (Tucker-
Davis Technologies). Sound levels for clicks and pure tones were calibrated using a one-quarter-inch microphone (model PCB-378C01, PCB Piezotronics). The calibration microphone was interfaced with a close-field speaker using a $2 \mathrm{~cm}$ plastic tube, which was placed in a sealed (sound isolated) syringe tube (the coupler). Connections between the speaker, tube, coupler, and microphone were tight-fitting to avoid inaccurate calibration. Calibration was performed using the Tucker-Davis Technologies program BioSigRZ. All calibration and ABRs were conducted in a sound-attenuating cubicle (ENV-022SV; Med Associates). Mice were kept under isoflurane anesthesia ( $3 \%$ in oxygen for induction, $1.5 \%$ for maintenance, and at a constant body temperature at $37^{\circ} \mathrm{C}$ maintained by a heating pad). For ABRs, click stimuli $(0.1 \mathrm{~ms}$ duration) and tone bursts ( $5 \mathrm{~ms}$ duration with $2.5 \mathrm{~ms}$ linear rise-fall time and $0 \mathrm{~ms}$ plateau) at $4,16,24$, and $32 \mathrm{kHz}$ were delivered. Evoked potentials were averaged over 1024 sweeps, and waveforms were filtered using a bandpass filter of 300-3000 Hz. ABR waveforms were recorded at decreasing intervals of $5 \mathrm{~dB}$ beginning with $90 \mathrm{~dB}$ for clicks. Auditory thresholds for click and pure tones were determined offline by identifying the lowest intensity level at which clear reproducible peak waveforms 1,2 , and 3 were visible in the averaged traces. ABRs were performed and analyzed blinded to the experimental condition.

Detection and quantification of c-Fos expression. Immediately following acoustic simulation, mice were anesthetized with a lethal dose of ketamine/xylazine and transcardially perfused with $10 \mathrm{ml}$ PBS followed by $30 \mathrm{ml}$ 4\% PFA/PBS. Brains were removed, postfixed in $4 \% \mathrm{PFA} / \mathrm{PBS}$ overnight at $4^{\circ} \mathrm{C}$, and incubated in $30 \%$ sucrose for $48-72 \mathrm{~h}$ at $4^{\circ} \mathrm{C}$. CN-containing sections $(30 \mu \mathrm{m}$ coronal) were cut with a cryostat (HM550). Entire $\mathrm{CN}$ was cut and sections with clear GCD selected, four sections per animal. Sections were incubated in blocking solution (5\% normal donkey serum, $2.5 \%$ Triton X-100 in PBS) for $1 \mathrm{~h}$ at room temperature and then incubated with rabbit anti-c-Fos (Oncogene Research Products, \#PC38) at 1:20,000 dilution overnight at room temperature. Following incubation with the primary antibody, sections were washed 3 times with PBS and then incubated with donkey anti-rabbit secondary antibody conjugated to Alexa-488 (Jackson ImmunoResearch Laboratories, 1:1000) for $1 \mathrm{~h}$ at room temperature. Sections were washed 3 times with PBS, incubated with NeuroTrace 530/613 Nissl stain (Thermo Fisher Scientific) for 5 min at room temperature, washed 3 times with PBS and coverslipped with Fluoromount G (Southern Biotechnology).

The number of c-Fos ${ }^{+}$neurons per section was quantified using ImageJ software (National Institutes of Health) with automated thresholding of the c-Fos signal and particle analysis. Nucleus size was assessed by measuring the size of the c-Fos signal within nuclei. Again, using ImageJ software $1.53 \mathrm{c}$ (National Institutes of Health; https://imagej.nih.gov/ij/index.html), the outer boundaries of the c-Fos signal were manually traced with a scale-calibrated image and then the area $\left(\mu \mathrm{m}^{2}\right)$ of the drawn ROI calculated with the analyze/measure function. Similarly, to measure the somatic area of c-Fos ${ }^{+}$neurons, the outer boundaries of the Nissl signal were manually traced for $\mathrm{c}-\mathrm{Fos}^{+}$neurons that could be clearly differentiated from neighboring neurons and the area of the drawn ROI $\left(\mu \mathrm{m}^{2}\right)$ was calculated with the analyze/ measure function. The area of the $\mathrm{CN}$ regions was analyzed in ImageJ using three sections each from 2 or 3 animals per genotype. Posteroventral CN (PVCN), DCN, DCN deep layers, and GCD were included in the analyses. $\mathrm{CN}$ area and c-Fos analyses were performed and analyzed blinded to genotype. 
Electrophysiological recordings from Type II afferents. Mice of either sex aged P8 were anesthetized with isoflurane (100\%, Vedco). After ensuring deep anesthesia with a foot pinch, the animal was decapitated, and cochlear turns were excised and mounted for recordings. Using a Dodt contrast-equipped Examiner Z1 microscope (Carl Zeiss) with a $20 \times, 1.0 \mathrm{NA}$ water immersion objective, 4-6 OHCs were aspirated to expose the Type II dendrites for giga-ohm seal voltage-clamp recording. Extracellular solution was perfused through the recording chamber at a rate of $2-3 \mathrm{ml} / \mathrm{min}$. The solution contained the following (in $\mathrm{mm}$ ): 5.8 potassium chloride, 150 sodium chloride, $1.3 \mathrm{cal}$ cium chloride, 0.9 magnesium chloride, 0.7 sodium phosphate, 5.6 glucose, 10 HEPES, $\mathrm{pH}$ 7.4. Pipette solution contained the following (in $\mathrm{mm}$ ): 20 potassium chloride, 110 potassium methanesulfonate, 0.1 calcium chloride, 5 magnesium chloride, 5 EGTA, 5 HEPES, 5 sodium-ATP, 0.3 sodium-GTP, and 5 sodium phospho-creatine, $\mathrm{pH} 7.2 ; 10 \mu \mathrm{M}$ AlexaFluor-488 or -594 hydrazide was included in the internal solution for imaging of dendritic structure following the recording. Neurotransmitter release from $\mathrm{OHCs}$ was stimulated by focal application of extracellular solution in which the potassium chloride concentration was elevated from 5.8 to $40 \mathrm{~mm}$, with a corresponding decrease in the sodium chloride concentration. The high potassium solution was applied via a large-bore pipette positioned close to the tissue. Recording electrodes were pulled from $1 \mathrm{~mm}$ borosilicate glass (WPI) and fire-polished to resistances of 6-10 $\mathrm{M} \Omega$. Recordings were performed using a Multiclamp 700B amplifier, pClamp version 10, and a Digidata 1440A (Molecular Devices). Data were sampled at $50 \mathrm{kHz}$ and low-pass filtered at $10 \mathrm{kHz}$. Membrane holding potential is given without liquid junction potential correction of $-9 \mathrm{mV}$. Following the recordings, the AlexaFluor fill was imaged under 2-photon excitation $(810 \mathrm{~nm}$, Intelligent Imaging Innovations: 3i). High-resolution $Z$ stacks of the tracer-filled dendrites were obtained using SlideBook 5.5-6.0 software (Intelligent Imaging Innovations: $3 \mathrm{i}$ ) and converted to maximum intensity projections. Recordings were performed blinded to genotype.

Data analyses and figure preparation. EPSCs were analyzed with MiniAnalysis software (Synaptosoft) or Clampfit 10 (Molecular Devices) blinded to genotype. Postsynaptic current (PSC) detection threshold was set at $2 \times$ the root mean square of the baseline noise. The rate of PSCs in baseline conditions was determined from the first minute of recording, at a holding potential of $-90 \mathrm{mV}$. The rate of PSCs in high potassium solution was determined from the first PSC following $40 \mathrm{~mm} \mathrm{KCl}$ solution application, through the subsequent $30 \mathrm{~s}$. Individual PSC traces were low-pass filtered at $2 \mathrm{kHz}$ for presentation in Figure 2. The 2-photon images of filled neuronal dendrites were contrast enhanced and traced in Photoshop CS2 (Adobe). Figures were prepared in GraphPad Prism 7 (GraphPad), Origin version 2020 (Origin Laboratories), and Adobe Illustrator (Adobe).

Statistical analyses. Analyses were performed using Origin version 2019 or version 2020 (Origin Laboratories) or GraphPad Prism 7 (GraphPad). In Type II SG afferent patch-clamp experiments, the PSC rates were non-normally distributed as determined by a Shapiro-Wilk test, so differences between genotypes were tested using a nonparametric Kruskal-Wallis ANOVA with post hoc Mann-Whitney $U$ test and Bonferroni correction for multiple comparisons. Differences in PSC kinetics between genotypes were tested by ANOVA with post hoc Tukey's test. The difference in acoustic startle response amplitudes by genotype were assessed by Student's $t$ test at each intensity with Welch's correction for unequal variances. ABR values were compared between groups using repeated-measures two-way ANOVA, with Bonferroni correction for multiple comparisons. The differences in $\mathrm{c}^{-\mathrm{Fos}^{+}}{ }^{+}$neuron counts by genotype were assessed using a one-way ANOVA with post hoc Tukey's test. The differences in $\mathrm{c}-\mathrm{Fos}^{+}$nuclear size distributions by genotype were assessed by a pairwise Kolmogorov-Smirnov test with Bonferroni correction. The differences in $\mathrm{CN}$ region areas were assessed by KruskalWallis ANOVA with post hoc Dunn's test. All data are shown as the mean \pm SEM (see Figs. 2-4, 7) unless otherwise stated.

\section{Results}

To generate mice that release vesicular glutamate from OHCs, but not IHCs, we first identified the vesicular glutamate transporters expressed by OHCs. Cochlear IHCs show robust immunoreactivity for VGluT3 from embryonic day 18 (E18) through adulthood (Seal et al., 2008). In contrast, OHCs show very weak immunoreactivity for VGluT3 and only at E18, the earliest age examined (Seal et al., 2008). Immunoreactivities to VGluT1 and VGluT2 were not detected in IHCs or OHCs at any age (Seal et al., 2008). The difficulty of detecting VGluT(s) in postnatal $\mathrm{OHCs}$ by immunolabeling may be because of the relatively low number of synaptic vesicles (Weisz et al., 2012), and hence low numbers of glutamate transporters in these cells. To circumvent these detection issues, we used a genetic labeling approach to identify the transporter isoform(s) expressed by OHCs. We crossed VGluT ${ }^{\text {Cre }}$ mice (Vglut ${ }^{\text {IRESCre }}$, Vglut2 ${ }^{\text {Cre }}$, and $\operatorname{Vglut}^{\text {IRESCre }}$ ) to the floxed tdTomato reporter mouse (Ai14) (Fig. 1) and then examined expression of the fluorescent red reporter at prehearing (P8) and adult (P35) ages. Expression of tdTomato fluorescence was clearly detected in OHCs of Vglut $3^{\text {IRESCre }}$ mice at both ages, but it was not detected in hair cells of Vglut $1^{I R E S C r e}$ mice at either age (Fig. $1 A$ ). With respect to VGluT2, surprisingly some OHCs were tomato ${ }^{+}$in the bacterial artificial chromosome (BAC) transgenic Vglut2 ${ }^{\mathrm{Cre}}$ mouse, but none was observed in the knockin Vglut $2^{I R E S-C r e}$ mouse line (Fig. 1A; Table 1).

As a second approach, we used RNAscope ISH to detect mRNA for the three VGluT isoforms in the cochleae at P8. Bright puncta were clearly observed in OHCs for Vglut3, but not for Vglut1 or Vglut2. As expected, puncta for Vglut1 and Vglut2 were clearly present in SG cell bodies (Fig. 1B).

To further resolve whether Vglut2 functions in OHCs, we performed whole-cell tight-seal recordings from the dendrites of Type II SG neurons using patch-clamp electrophysiology (Weisz et al., 2009) in P8 mice that lack only VGluT3 or both VGluT2 and VGluT3 in OHCs. Global VGluT3 KO $\left(\right.$ Vglut $\left.^{-1-}\right)$ mice are deaf (Seal et al., 2008; Kim et al., 2019) but survive to adulthood. Global VGluT2 KOs, however, are embryonic lethal. Thus, we crossed the OHC-specific Cre line (Prestin ${ }^{\text {CreERT2 }}$ ) to the conditional VGluT2 KO ( Vglut $\left.^{f l / f l}\right)$ to selectively delete this isoform from OHCs. The expected expression of Cre recombinase in OHCs of the Prestin ${ }^{\text {CreERT2 }}$ mouse line was confirmed by crossing the line to the tdTomato reporter (P8) (Fig. 1C). We then performed whole-cell tight-seal recordings from Type II SG afferent dendrites in acute cochlea preparations from P8 mice with normal $\mathrm{OHC}$ glutamate release (control $\mathrm{Vglut}^{+/+}$), mice with a global KO of VGluT3 $\left(\right.$ Vglut $\left.^{-1-}\right)$, or mice lacking both VGluT2 and VGluT3 in OHCs (Prestin ${ }^{\text {CreERT2 }}$; Vglut3 ${ }^{-1-}$; $V_{\text {glut }} 2^{\mathrm{fl} / \mathrm{fl}}$, or Prestin ${ }^{\text {CreERT2 }}$;Vglut $3^{f l / f l}$;Vglut $2^{f l / f l}$, the latter mice lack VGluT2 and VGluT3 only in the OHCs) (Fig. 2). Consistent with previous work in rats, recordings from Type II SG afferent dendrites in WT mice showed occasional spontaneous, 
monophasic PSCs in normal $(5.8 \mathrm{~mm}$ $\mathrm{KCl})$ extracellular solution $(0.14 \pm 0.08$ PSC/s, $n=6$ cells; Fig. 2A,E). Depolarization of $\mathrm{OHCs}$ by application of high potassium $(40 \mathrm{~mm})$ extracellular solution significantly increased the rate of PSCs (3.46 $\pm 2.49 / \mathrm{s}, n=6$ neurons; Fig. $2 A, D)$. In recordings from VGluT3 $\mathrm{KO}$ mice, PSCs were not observed in 8 of 12 Type II SG afferent dendrites. There was a significant decrease in the rate of PSCs in Type II SGN dendrites in VGluT3 KO compared with WT animals in both normal (5.8 $\mathrm{mm})$ and elevated (40 $\mathrm{mm})$ potassium solutions (control Vglut3 $3^{+/+}$vs Vglut $^{-1}$ -: $5.8 \mathrm{~mm} \mathrm{~K}^{+}$solution: Mann-Whitney $U$ test: $U=62, Z=3.03, p=0.0025 ; 40 \mathrm{~mm}$ $\mathrm{K}^{+}$solution Mann-Whitney $U$ test: $U=64, Z=2.75, p=0.0059)$. For the four Type II SGN dendrites that showed PSCs, the size and kinetics were similar to PSCs observed in WT mice (PSC amplitude: WT $20.4 \pm 4.6 \mathrm{pA}$, VGluT3 KO $19.8 \pm$ $5.5 \mathrm{pA}, p=0.85 ; 10-90$ rise time: WT $0.96 \pm 0.30 \mathrm{~ms}$, VGluT3 KO $1.04 \pm 0.34$ $\mathrm{ms}, \quad p=0.71$; decay time constant $3.20 \pm 1.42 \mathrm{~ms}$, VGluT3 KO $2.69 \pm$ $1.25 \mathrm{~ms}, p=0.57$, wt 862 PSCs in 6 cells, VGluT3 KO 38 PSCs in 4 cells; Fig. 2B,D, $E)$. The absence of PSCs in most, but not all, Type II SG afferents of VGluT3 KO mice indicates that VGluT2 may be present in at least some OHCs at this age.

To test whether VGluT2 generates the remaining PSCs in VGluT3 $\mathrm{KO}$ mice, we measured potassium-evoked glutamate currents in Type II afferents of mice lacking both VGluT2 and VGluT3 in OHCs. In two mouse lines in which both VGluT2 and VGluT3 were knocked out from OHCs, no PSCs were detected in Type II afferents under both baseline and elevated potassium conditions ( $n=5$ neurons; Fig. 2C,D). To confirm that the absence of PSCs in VGluT KO animals was because of loss of glutamate release from $\mathrm{OHCs}$ and not because of an absence of postsynaptic receptors in Type II SGN, kainate $(100 \mu \mathrm{M})$ was focally applied during recordings from Type II SGN dendrites in Prestin ${ }^{\text {CreERT2 }}$; Vglut $3^{\text {fl/fl }} ; V_{\text {glut }} 2^{\text {flfl }}$ mice. In some recordings, cyclothiazide $(100 \mu \mathrm{M})$ was added to the extracellular solution to prevent receptor desensitization. Kainate evoked inward currents in 5 of 5 Type II SGN dendrites. The response to kainate was blocked by NBQX $(10 \mu \mathrm{M})$ (Fig. 2F), confirming that the kainate response was mediated by AMPARs. This result confirms that the loss of PSCs in Type II SGN recordings from VGluT KO animals was because of a loss of glutamate release and not to a deficit in postsynaptic AMPAR function. During the recordings, a fluorescent neuronal tracer was included in the pipette solution to label the recorded Type II SG dendrites, which

A

B

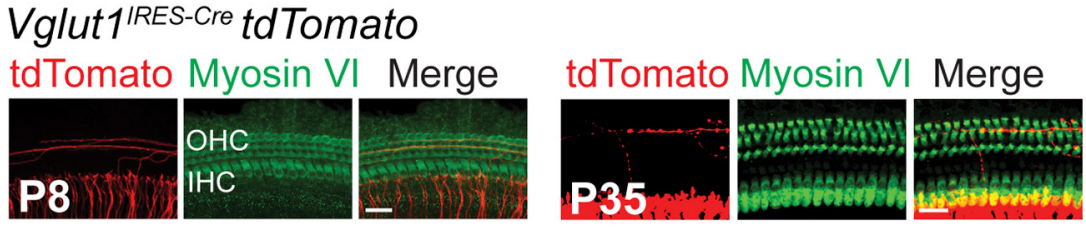

Vglut2 ${ }^{\text {Cre }}$ tdTomato

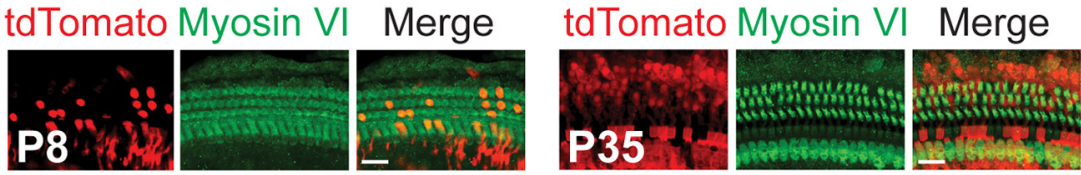

Vglut2 IRES-Cre $^{\text {tdTomato }}$

tdTomato Myosin VI Merge
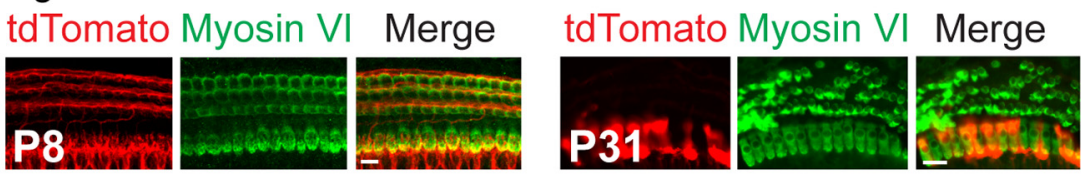

Vglut3 $3^{\text {RESS-Cre }}$ tdTomato tdTomato Myosin VI Merge

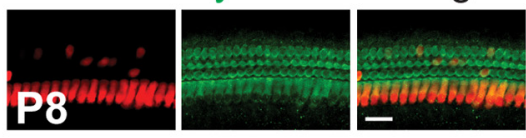

tdTomato Myosin VI Merge
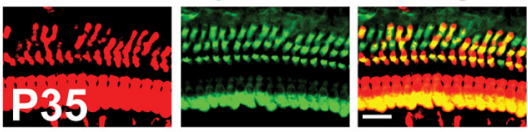

Vglut1 in situ

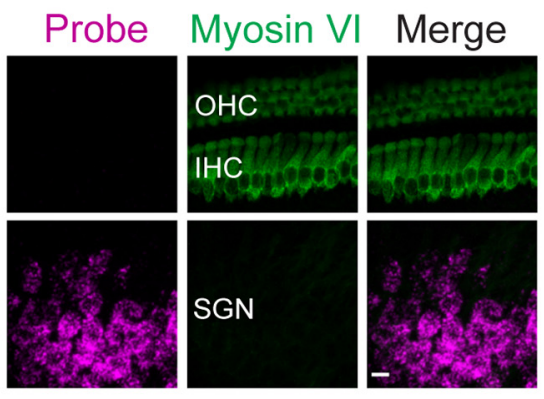

Vglut3 in situ

Vglut2 in situ
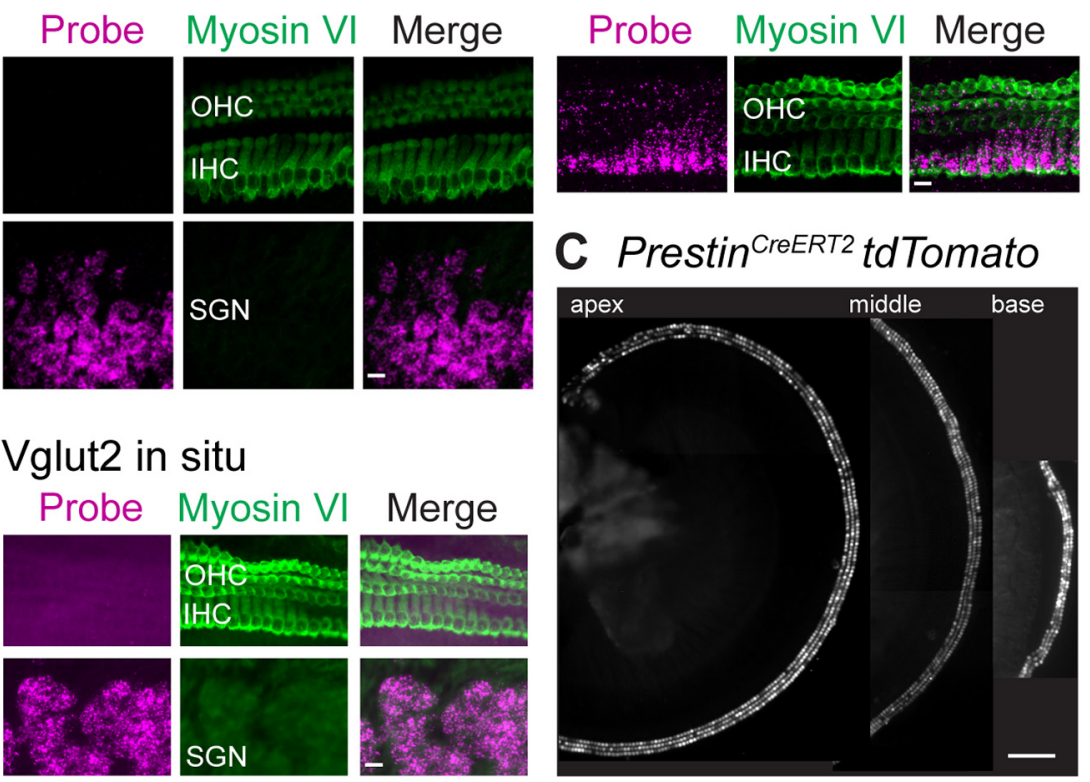

Figure 1. Analysis of Vglut expression in $\mathrm{OHCs}$. A, The Cre-dependent tdTomato (red) fluorescent reporter mouse (Ai14) crossed to Vglut $7^{\text {IRESCre }}$, Vglut2 $^{\text {(re }}$, Vglut2 $^{\text {IRESCre }}$, or Vglut ${ }^{\text {IRESCre }}$ mice indicates expression of VGluT3 in OHCS of the cochlea at P8 and P35, and VGluT2 expression in occasional OHCs in the Vglut2 ${ }^{\text {Cre }}$, but not the Vglut2 ${ }^{\text {IRESCre }}$ mouse lines. Hair cells are labeled with myosin VI (green). Scale bar, $20 \mu \mathrm{m}$. B, ISH for Vgluts 1-3 in OHC, IHC, and SGN in sections of P8.5 mice. Hair cells are labeled with myosin VI (green). Scale bar, $20 \mu \mathrm{m}$. C, Cochlea of P8 Prestin ${ }^{\text {(reERT2i }}$ itdomato mouse injected with tamoxifen shows expression of the fluorescent reporter in $\mathrm{OHCs}$ of the cochlear apex, mid-turn, and base. Scale bar, $200 \mu \mathrm{m}$.

were then imaged using 2-photon microscopy. Qualitatively, no morphologic differences were noted for the Type II dendritic structures between the three genotypes (Fig. 2G). Together, our results indicate that VGluT3 is the predominant isoform used by OHCs, with a minor contribution by VGluT2, at least at early postnatal ages. 
A

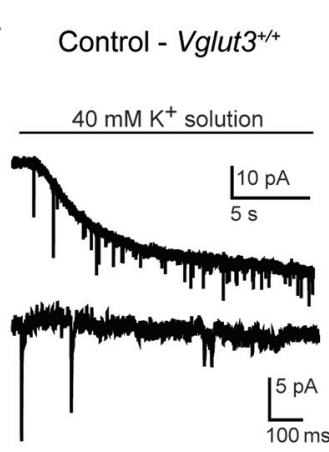

B

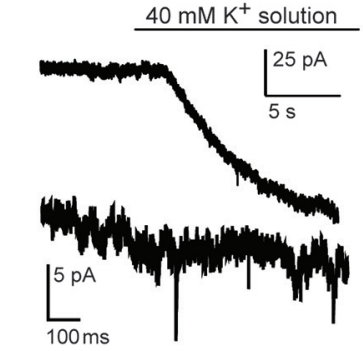

C Prestin CreERT2 Vglut3 ${ }^{-/-}$Vglut2 $2^{\text {flif }}$

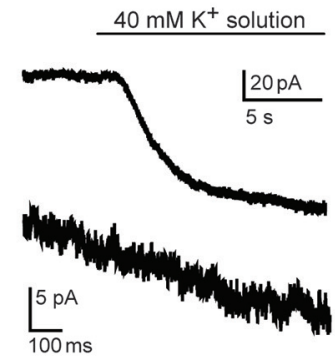

E

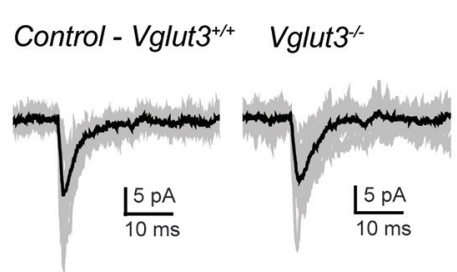

$\mathbf{F}$

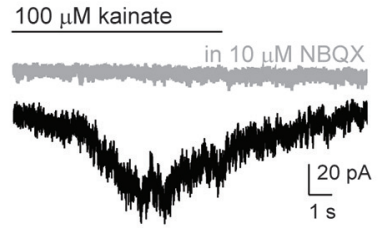

D

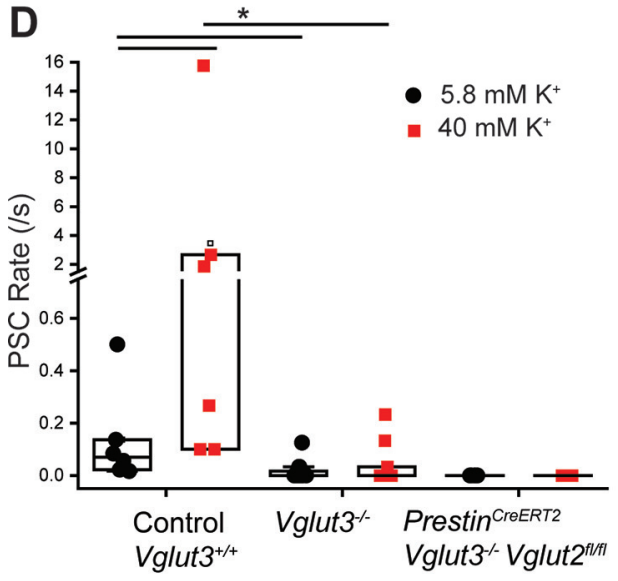

G

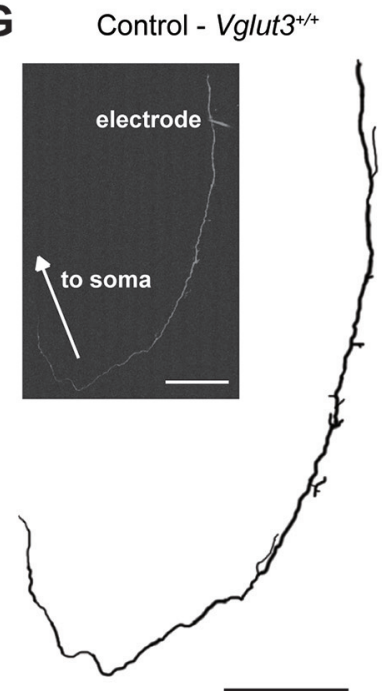

Vglut $3^{--}$

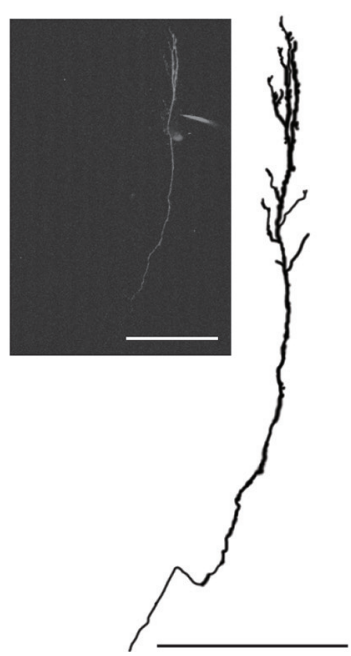

Prestin CreERT2 Vglut3 ${ }^{--}$Vglut2 $2^{\text {flfl }}$
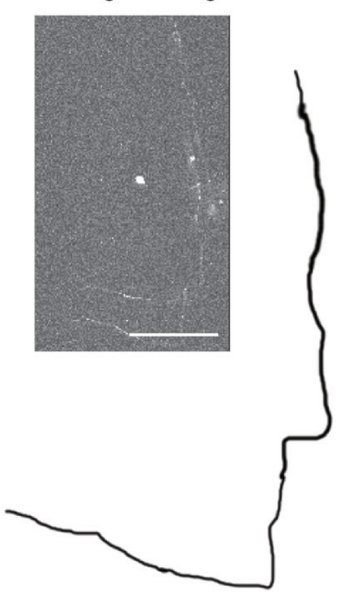

Figure 2. VGluT2 and VGluT3 mediate glutamate release from cochlear OHCS. A, Voltage-clamp recording from a control $\left(\right.$ Vglut $\left.3^{f / f f}\right)$ Type II SG afferent dendrite. Top, Application of extracellular solution with elevated $40 \mathrm{~mm}$ potassium generates a sustained inward current, and PSCs in the Type II afferent. Bottom, Magnification of selected PSCS. B, Voltage-clamp recording from a Type II SG afferent dendrite of a Vglut $3^{-1-}$ mouse. Top, Application of $40 \mathrm{~mm}$ potassium solution generates an inward current and PSCs in the Type II SG afferent. Bottom, Magnification of selected PSCS. C, Voltage-clamp recording from a Type II

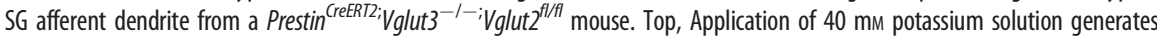
an inward current in the dendrites but does not generate PSCs in the Type II SG afferent. Bottom, Magnification of trace. $\boldsymbol{D}$, Scatter plot of PSC rate in normal $(5.8 \mathrm{~mm})$ and elevated $(40 \mathrm{~mm})$ potassium solution. Each dot represents one cell. Box represents median and quartiles. $* p<0.05$. E, Example traces of PSCs recorded from a Vglut ${ }^{+/+}$WT (top) and Vglut ${ }^{-/-}$mouse Bottom, Ten traces overlaid (gray). Black represents average of 10 traces. $\boldsymbol{F}$, Voltage-clamp trace from a Type II SG dendrite from a PrestinCreERT2;Vglut3/;Vglut2fl/fl mouse. Focal application of $100 \mu \mathrm{M}$ kainate evokes an inward current (black), which is blocked by $10 \mu \mathrm{M}$ NBQX (gray). G, Morphology of example Type II SG neuron dendrites from which recordings were performed. Dendrites were filled with AlexaFluor-488 or -594 hydrazide via the recording pipette (visible, "electrode") and imaged with 2-photon excitation. Traced neurons are shown for better visibility. Insets, Maximum intensity projections of each neuron (left, middle, right). Right inset, two dendrites are visible from separate recordings. Scale bars, $100 \mu \mathrm{m}$.

Glutamate release by $\mathrm{OHCs}$ induces activity in $\mathrm{CN}$ neurons

Tracing studies of the central terminals of Type II SGNs suggest that these fibers innervate neurons within the GCD of the CN (Brown et al., 1988; Berglund et al., 1996; Benson and Brown, 2004). However, it is not known whether OHC-mediated glutamate signaling through the Type II SGN induced by moderate or even intense sound leads to the activation of any of the cells in the $\mathrm{CN}$ or specifically to activation of cells within the GCD.

To investigate sound-evoked activation of $\mathrm{CN}$ neurons via the OHC-Type II SG pathway, we created a mouse line that lacks VGluT3 in IHCs, but still expresses VGluT3 and potentially VGluT2 in OHCs. In this line, OHCs, but not IHCs, are able to release vesicular glutamate. To generate the line, we used Vglut $^{\text {Cre }}$ BAC transgenic mice that show an unexpectedly restricted expression pattern for the Cre recombinase (Grimes et al., 2011). In Vglut $3^{\text {Cre }}$ BAC mice crossed to the tdTomato reporter line, in contrast to the knockin line (Vglut $3^{\mathrm{IRESCre}}$ ) in which Cre is expressed in IHCs and OHCs (Fig. 1), the tdTomato reporter in the Vglut $3^{\mathrm{Cre}} \mathrm{BAC}$ is robustly expressed only by IHCs, and not OHCs (Fig. $3 A$ ). The under-representation of the true expression pattern of the target gene is not unusual for BAC transgenic mouse lines (Schmidt et al., 2013). We crossed the Vglut ${ }^{\text {Cre }}$ BAC transgenic mice to the conditional VGluT3 KO $\left(V g l u t 3^{f l / f l}\right)$ line to produce Vglut ${ }^{\mathrm{Cre}}$ Vglut $3^{\mathrm{fl} / \mathrm{fl}}$ mice, which lack VGluT3 in IHCs but not OHCs. It should be noted that insertion of the Cre gene at the translational start site for Vglut3 in the BAC transgene disrupts production of functional VGluT3 protein from the transgene (Grimes et al., 2011; Peirs et al., 2015). Deletion of VGluT3 in IHCs was confirmed by a lack of immunoreactivity to the transporter as well as the absence of an acoustic startle response (Fig. 3B,C) as previously reported for global VGluT3 KO mice (Seal et al., 2008). Additionally, successful Cre-dependent loss of VGluT3 function in other cell types using the Vglut3 $3^{f / f l}$ line has previously been reported (Divito et al., 2015; Peirs et al., 2015).

We measured the induction of c-Fos in the $\mathrm{CN}$ in response to one hour of moderate intensity, nondamaging ( $80 \mathrm{~dB}$ SPL) or intense ( $115 \mathrm{~dB}$ SPL) constant broadband noise $(3-30 \mathrm{kHz})$. To first assess whether exposure to these 
stimuli affected hearing thresholds (signifying damage), we measured $\mathrm{ABR}$ to broadband click and individual frequencies $(4-32 \mathrm{kHz})$ in $\mathrm{Vglut} 3^{\mathrm{fl} / \mathrm{fl}}$ littermate controls before and 2 weeks after sound exposure (Fig. 4). In the case of $80 \mathrm{~dB}$ SPL, no changes were observed in the $\mathrm{ABR}$ thresholds to clicks or pure tones $\left(F_{(6,84)}=0.2361 ; p=0.963\right.$; Fig. $4 A, B)$, suggesting that this exposure does not cause cochlear damage. In contrast, but as expected, $115 \mathrm{~dB}$ SPL exposure resulted in elevated ABR thresholds to the click stimuli $(17 \pm 3 \mathrm{~dB}$ SPL $)$ and to the pure tones that varied depending on test frequency $(4-32 \mathrm{kHz})\left(F_{(6,70)}=21.23\right.$; $p<0.001$; Fig. 4C,D). Examining the cochlea of mice exposed to $115 \mathrm{~dB}$ SPL by staining with Alexa647-conjugated phalloidin showed that IHCs and OHCs were not lost, and stereocilia were grossly normal (Fig. 4E).

To analyze c-Fos in the CN, mice were killed immediately after the 80 and $115 \mathrm{~dB}$ SPL sound exposures and $\mathrm{CN}$ sections stained with an anti-c-Fos antibody. At both sound intensities, mice with intact glutamate release from OHCs, but absent glutamate release from IHCs $\left(\right.$ Vglut $\left.^{\mathrm{Cre} ;} \mathrm{Vglut} \mathrm{f}^{f l / f l}\right)$, showed c-Fos induction primarily within the GCD. In particular, c-Fos ${ }^{+}$ nuclei were found in the region between the PVCN and DCN (subpeduncular corner), and within the fusiform and deep layers of the DCN (Figs. 5A, 6A). Few c-Fos ${ }^{+}$cells were detected outside these granule cell-containing regions. This is in contrast to the littermate controls with intact glutamate release from both IHCs and OHCs $\left(\right.$ Vglut $\left.{ }^{f l / f l}\right)$, which showed c-Fos ${ }^{+}$neurons in the deep layers of the DCN and GCD and some c-Fos ${ }^{+}$cells in the VCN as previously shown in rats (Yang et al., 2005) (Figs. 5B, 6B). Importantly, while the number of c$\mathrm{Fos}^{+}$neurons in the CN of Vglut ${ }^{\mathrm{Cre} ;} \mathrm{Vglut}^{\text {fl/fl }}$ mice was significantly less than in the $\mathrm{CN}$ of $\operatorname{Vglut}^{\mathrm{f} / \mathrm{l} / \mathrm{l}}$ positive control mice, it was significantly greater than in the $\mathrm{CN}$ of negative control mice which lack glutamate release from both IHCs and $\mathrm{OHCs}$ (Prestin $^{\text {CreERT2; }}$ Vglut3 $^{-/-;}$Vglut2 $^{\mathrm{fl} / \mathrm{fl}}$ mice) (Fig. 7A) as well as in the CN of Vglut $^{\mathrm{Cre} ;} \mathrm{Vglut}^{\mathrm{fl} / \mathrm{fl}}$ mice not exposed to sound (115 dB SPL stimulation: Vglut $3^{f l f f}$ : $74.3 \pm 16.2, n=20$ sections from 5 mice, Vglut $3^{\text {Cres }}{ }^{\text {Vglut } 3^{\text {fllfl }}: 23.6 \pm 8.5, n=28 \text { sections from }}$ 7 mice, Prestin ${ }^{\text {CreERT2; }}$ Vglut $^{-1-} ;$ Vglut $^{\mathrm{fl} / \mathrm{fl}}: 4.8 \pm$ 1.9, $n=24$ sections from 6 mice, one-way ANOVA: $p=2.7 \mathrm{E}-8 ; \quad 80 \mathrm{~dB}$ SPL stimulation: Vglut $3^{\text {flffl }}$ : $44.8 \pm 1.3, n=12$ sections from 3 mice, $V g l u t 3{ }^{C r e}$; $V_{\text {glut }}{ }^{\text {flflfl }}: 20.3 \pm 5.7, n=16$ sections from 4 mice,

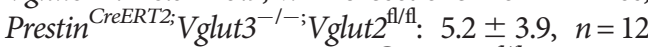
sections from 3 mice, Vglut $3^{\text {Cre; }}$ Vglut $3^{\text {fl/fl }} 0 \mathrm{~dB}$ SPL stimulation: $1.2 \pm 1.1, n=12$ sections from 3 mice; one-way ANOVA: $p=6.4 \mathrm{E}-6)$. Although the size of the $\mathrm{CN}$ is smaller in Vglut $3^{\mathrm{Cres}} \mathrm{Vglut} 3^{\mathrm{fl} / \mathrm{fl}}$ mice compared with control Vglut3 $3^{f / f l}$ (control Vglut $3^{f / f}$ : $458,230.0 \pm 58,691.0 \mu^{2}, n=7$ sections from 3 mice, Vglut $^{\mathrm{Cre} ;}$ Vglut $^{\text {flflf }}: 441,692.9 \pm 53,963.6 \mu \mathrm{m}^{2}$, $n=8$ sections from 3 mice, median \pm MAD, Kruskal-Wallis ANOVA with post hoc Dunn's test $p=0.00879$ ), the size of the GCD was not different between genotypes (control Vglut $3^{f l f l}: 64,577.4$
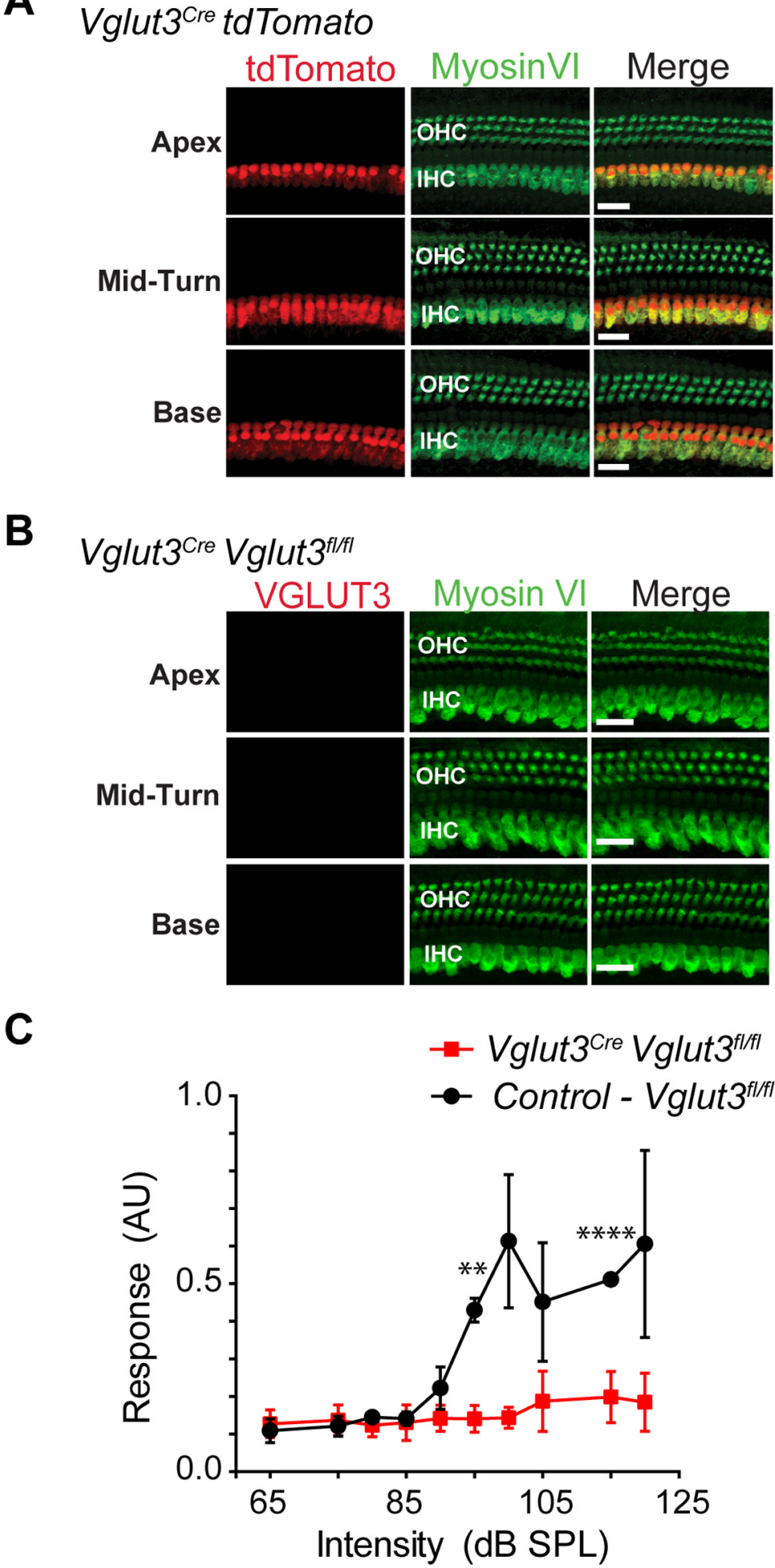

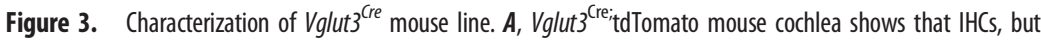
not $\mathrm{OHCs}$, exhibit tdTomato fluorescence (red) in apex, mid-turn, and base of the cochlea of P35 mice. Hair cells are immunostained for myosin VI (green). Scale bar, $20 \mu \mathrm{m}$. B, No VGluT3 immunoreactivity is observed in the IHCs of Vglut $3^{\text {Cre }}$ Vglut $3^{\mathrm{fl} / \mathrm{fl}}$ mice. Hair cells were also immunostained for myosin VI (green). Scale bar, $20 \mu \mathrm{m}$. C, Acoustic startle response is absent in the Vglut ${ }^{\text {(ree }} V$ glut $^{\text {fl/ffl }}$ mice $(n=6)$, but not control (Vglut $3^{\mathrm{fl} / \mathrm{fl})}$ littermates $(n=4)$. AU, Arbitrary units. Data are mean \pm SEM. $* * p<0.01$. $* * * * p<0.0001$.

$\pm 16,635.7 \mu \mathrm{m}^{2}$, Vglut $^{\text {Cres }}{ }^{\text {Vglut }} 3^{\text {flffl }}: 66,910.9 \pm 18,714.6 \mu \mathrm{m}^{2}$, median \pm MAD, Kruskal-Wallis ANOVA with post hoc Dunn's test $p=0.34$ ). In some sections, Nucleus $Y$, which receives synaptic input from the vestibular sacculus (Frederickson and Trune, 1986), was 

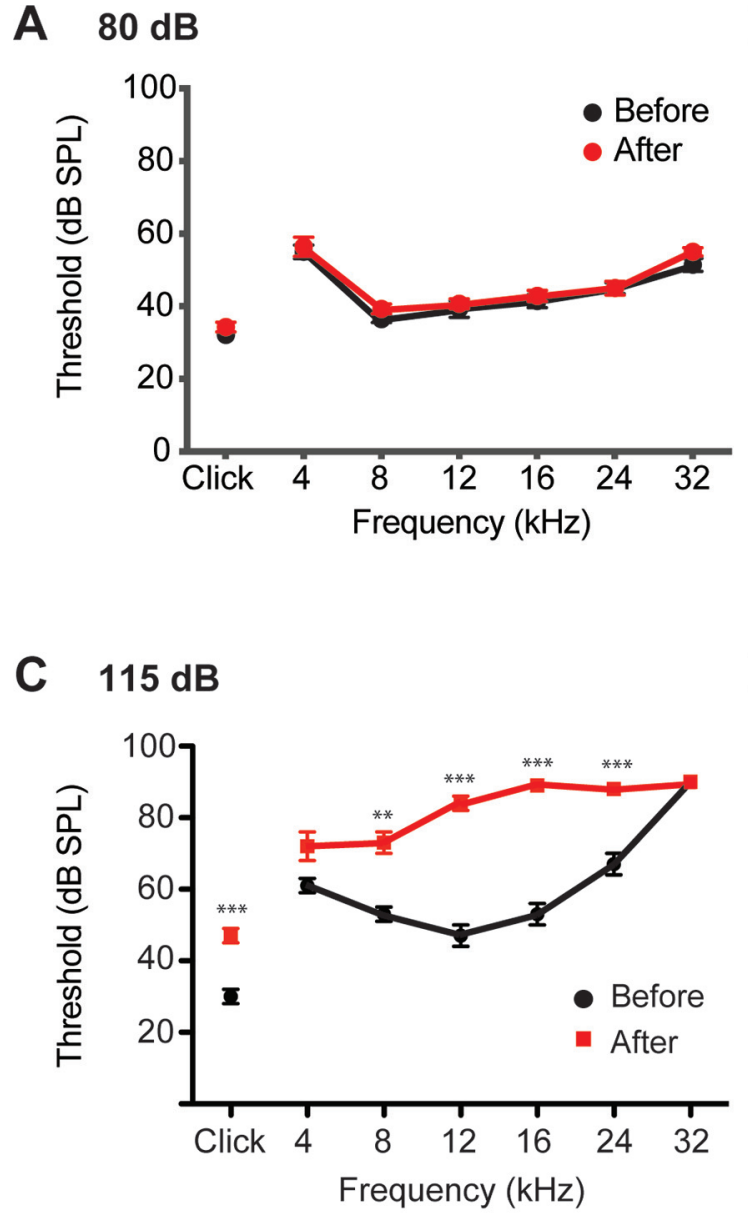

B Pre-exposure Post-80 dB SPL

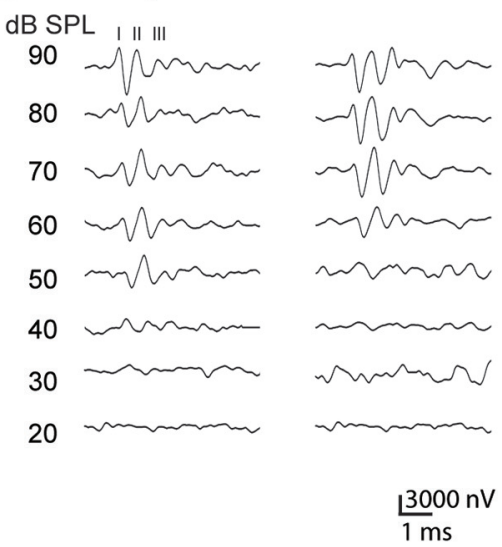

E

D Pre-exposure Post-115 dB SPL dB SPL
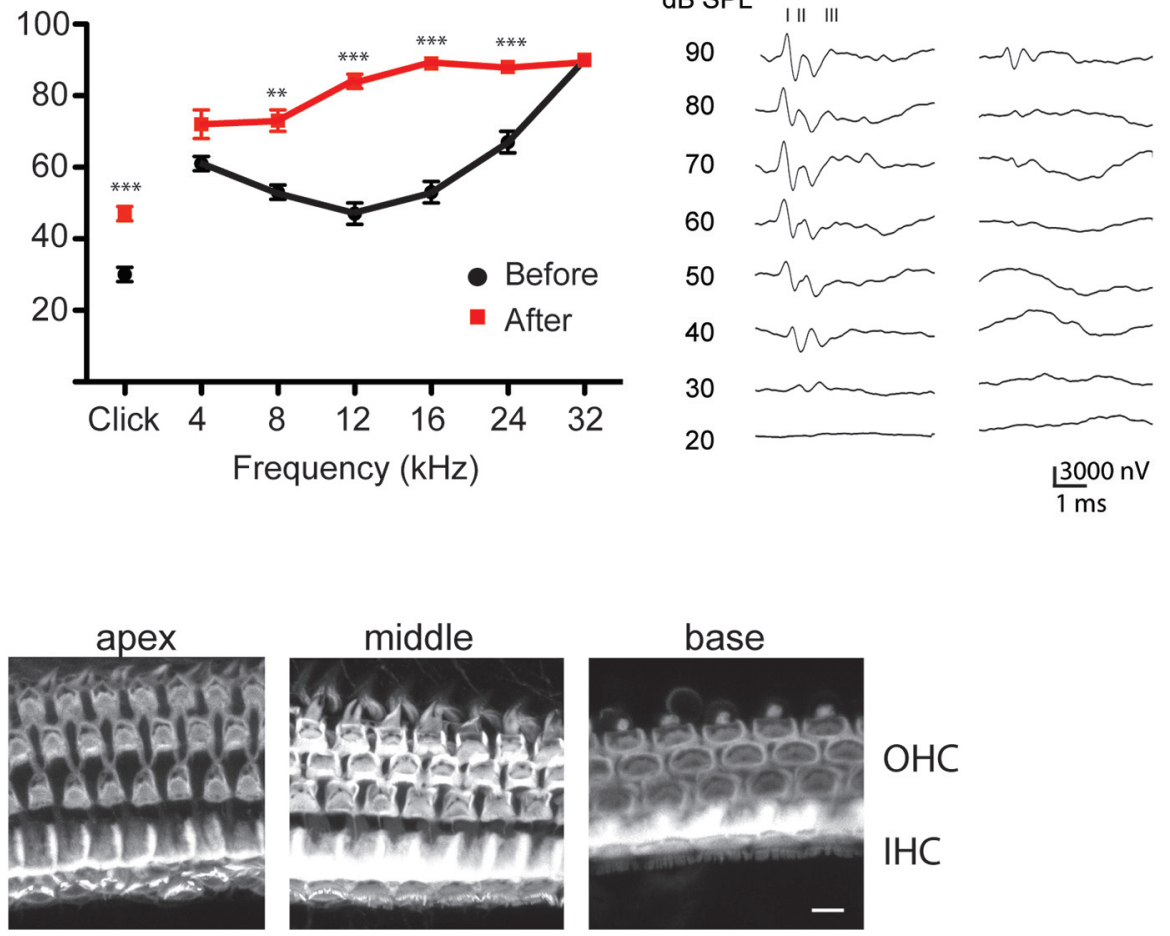

Figure 4. Hearing function after noise exposure. ABR thresholds measured before and 2 weeks after exposure to $(\boldsymbol{A}, \boldsymbol{B}) 80 \mathrm{~dB} S P L$ or $(\boldsymbol{C}, \boldsymbol{D}) 115 \mathrm{~dB} S P L$ for $1 \mathrm{~h}$ in Vglut $3^{f / f / t}$ mice. $\boldsymbol{B}, \boldsymbol{D}$, Representative traces. Numbers above traces indicate ABR wave number. Data are mean \pm SEM; $n=6$ mice. $\boldsymbol{E}$, Phalloidin staining of cochlea of Vglut $3^{f / f f l}$ mice 2 weeks after $115 \mathrm{~dB}$ SPL noise exposure. Scale bar, $10 \mu \mathrm{m}$. $* * p<0.01$. $* * * p<0.001$.

visible. c-Fos ${ }^{+}$nuclei were rarely observed in Nucleus $\mathrm{Y}$ in mice of any genotype exposed to either 80 or $115 \mathrm{~dB}$ SPL sound (Vglut $3^{f l f l}$ : $n=4$ sections, Vglut ${ }^{\text {Cre; }}$ Vglut $3^{\text {fl/fl }}: n=11$ sections, Prestin ${ }^{\text {CreERT2; }}$ Vglut $^{-/-} ; V_{\text {glut }}{ }^{\mathrm{Al} / \mathrm{ft}}: n=11$ sections, Kruskal-Wallis ANOVA $p=1$ ) (Fig. 6D-Diii), which suggests that this sound exposure is not activating vestibular afferent neurons from the sacculus. Together, these data show, for the first time, that acoustic information is transmitted to the brain via $\mathrm{OHC}$ glutamate release onto Type II SG afferents at moderate, nondamaging ( $80 \mathrm{~dB} \mathrm{SPL})$ as well as intense (115 dB SPL) levels of sound.

The GCD is composed of at least three small cell types ( $\leq 10 \mu \mathrm{m}$ soma diameter), granule cells, unipolar brush cells, and chestnut cells, as well as at least one larger cell type, the Golgi cells (Mugnaini et al., 1980a,b; Weedman et al., 1996). To provide insight into which of these types of neurons are activated by Type II SG neurons, we measured the nucleus sizes of $\mathrm{c}-F o s^{+}$neurons in the GCD of ${ }_{\text {Vglut }}{ }^{\text {Cre; }}$ Vglut $3^{\text {fl/fl }}$ mice and the Prestin ${ }^{\text {CreERT2; }}{ }^{\text {Vglut }}{ }^{-1}$ ${ }^{-;}$Vglut $2^{\mathrm{fl} / \mathrm{fl}}$ negative control mice. Though differing in their distribution, the nuclei sizes in both genotypes ranged from $\sim 5$ to $90 \mu^{2}$ (Fig. $7 B, C$ ), suggesting sound-driven $\mathrm{c}$-Fos expression in cell types of different sizes. In a subset of cells in which the soma could be clearly distinguished from surrounding cells, both the nuclear size and soma size were measured. Cells with small nuclei (up to $\sim 30 \mu \mathrm{m}^{2}$ ) had small, similarly sized somata, indicative of granule, chestnut, and unipolar brush cells, which have very small somatic cytoplasms (Mugnaini et al., 1980a; Floris et al., 1994; Weedman et al., 1996). The remaining larger cells showed 


\section{0 dB SPL Sound Exposure}

\section{Vglut3 $^{\text {Cre }}$ Vglut3 $3^{\text {ftrf }}$}
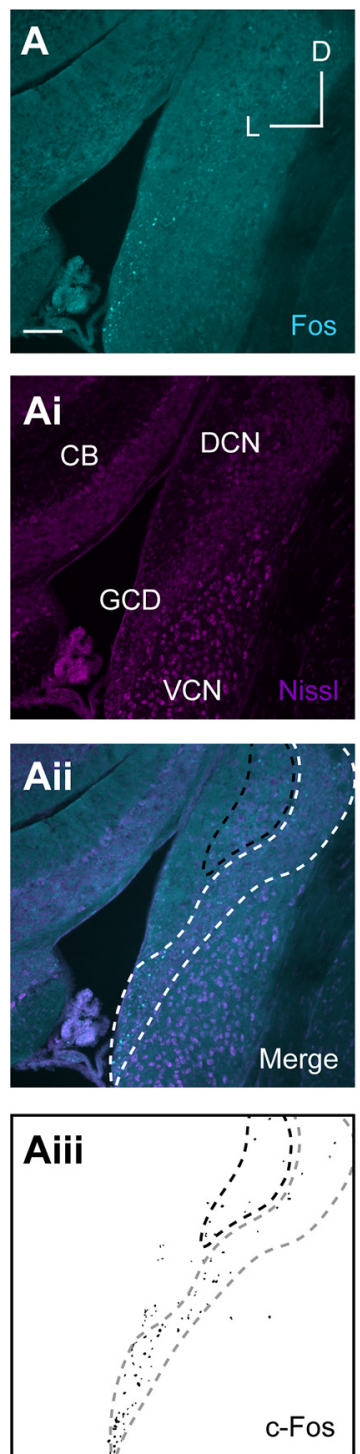

\section{Positive control}

Vglut $3^{\text {fl/fl }}$
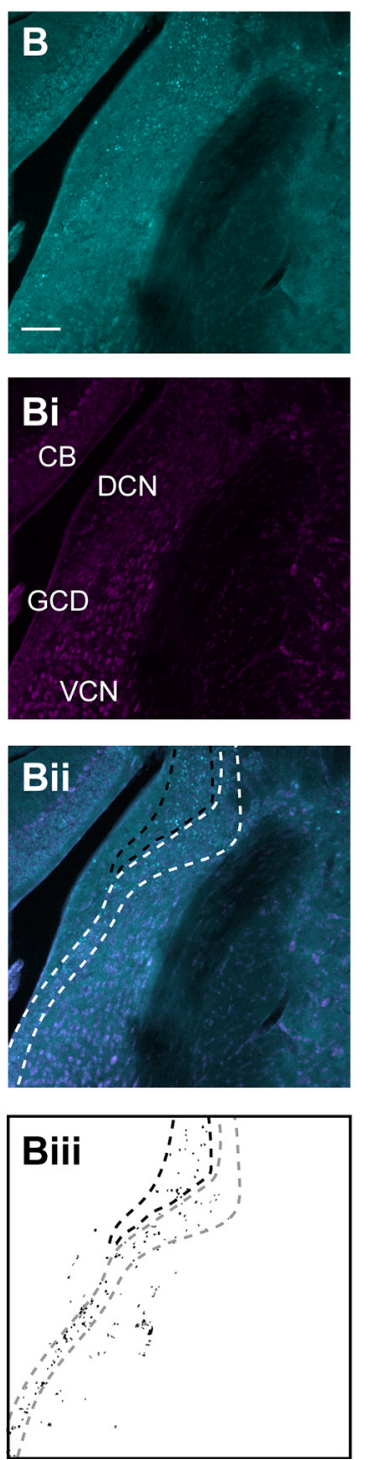

Negative control

Prestin CreERT2

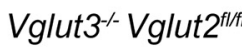
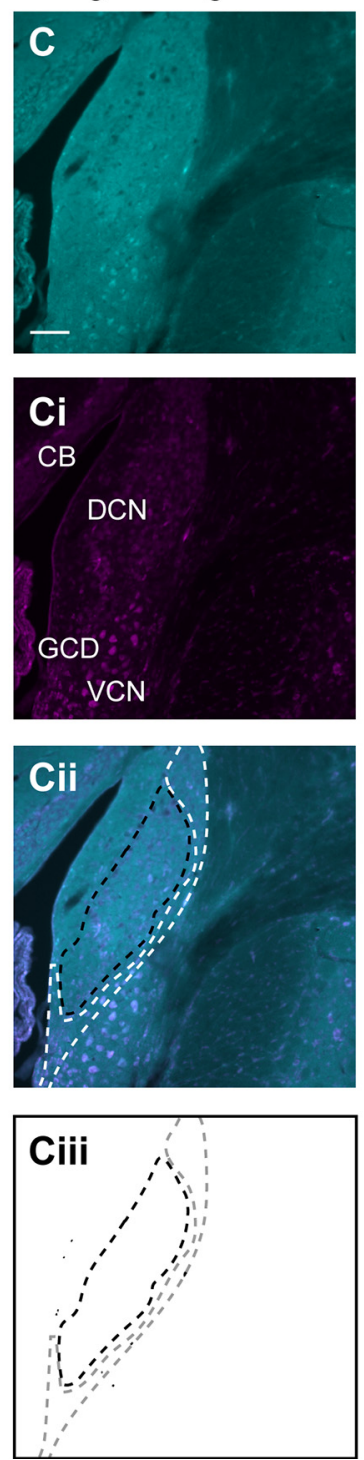

\section{No Sound Exposure}

\section{Vglut3 $^{\text {cre }}$ Vglut $^{\text {flftil }}$}
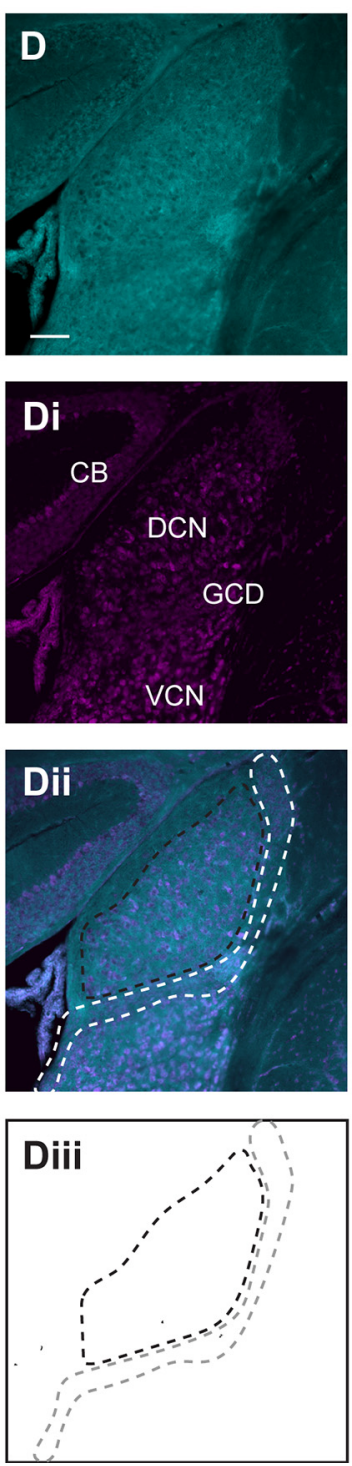

Figure 5. Sound-induced expression of C-Fos in the $\mathrm{CN}$ in response to a moderate nondamaging, $80 \mathrm{~dB}$ SPL, level of sound, or to no sound stimulus. $\boldsymbol{A}$, Representative images from Vglut $3^{\mathrm{Cre} ;} \mathrm{Vglut} \mathrm{f}^{\mathrm{fl} / \mathrm{fl}}$ mouse following sound exposure show c-Fos immunoreactivity (cyan) restricted to the GCD. Ai, Nissl staining (magenta). Aii, Merge of cyan and magenta channels. CB, Cerebellum. Aiii, Mask of C-Fos signal from A. Aii-Dii, Region enclosed by white dashed line indicates GCD. Region enclosed by black dashed line indicates regions of the DCN that also contain granule cells. $\boldsymbol{B}$, Representative image of the $\mathrm{CN}$ of Vglut ${ }^{\text {fl/fl }}$ (positive control) mouse subjected to $80 \mathrm{~dB}$ SPL sound exposure shows $\mathrm{C}-\mathrm{Fos}$ immunoreactivity (cyan) throughout DCN and GCD.

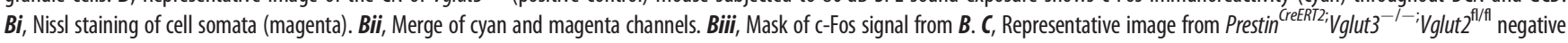
control mouse following sound exposure indicates background levels of c-Fos immunoreactivity (cyan). Ci, Nissl staining (magenta). Cii, Merge of cyan and magenta channels. Ciii, Mask of cFos signal from C. D, Representative image from Vglut $3^{\text {Cre }} \mathrm{Vglut} 3^{\mathrm{fl} / \mathrm{fl}}$ mouse that was not exposed to sound indicates background levels of c-Fos immunoreactivity (cyan). Di, Nissl staining (magenta). Dii, Merge of cyan and magenta channels. Diii, Mask of c-Fos signal from D. Scale bars, $100 \mu \mathrm{m}$.

somatic areas that reached up to $140 \mu \mathrm{m}^{2}$, although these larger cells show a weak relationship between nuclear and soma size. The nuclear size distributions of the cells expressing c-Fos in negative control Prestin ${ }^{\text {CreERT2; }}$ Vglut $^{-/-;} V_{\text {glut }} 2^{\mathrm{fl} / \mathrm{fl}}$ mice exposed to either 80 or $115 \mathrm{~dB}$ SPL sound were toward the smaller end of the distribution observed in $\mathrm{Vglut}{ }^{\mathrm{Cre}}$; $V_{\text {glut }}{ }^{f l / f l}$ mice (Fig. $7 B, C$ ). Exposure to $115 \mathrm{~dB}$ SPL white noise significantly shifted the distribution of $\mathrm{c}-\mathrm{Fos}^{+}$nucleus measurements to larger sizes (pairwise Kolmogorov-
Smirnov with Bonferroni correction, comparison considered significant if $p<0.0083$; Fig. $7 B, C)$. Activity in larger neurons suggests activation of additional $\mathrm{CN}$ circuitry by intense levels of sound, potentially including Golgi cells, which have a slightly larger nucleus and larger soma diameter $(>15 \mu \mathrm{m})$ (Mugnaini et al., 1980a). These results indicate that, at both moderate and intense sound levels, glutamate release from OHCs can lead to the activation of a diverse group of cell types in the CN GCD. 
Vglut3 $^{\text {Cre }}$ Vglut3 ${ }^{\text {fl/fI }}$
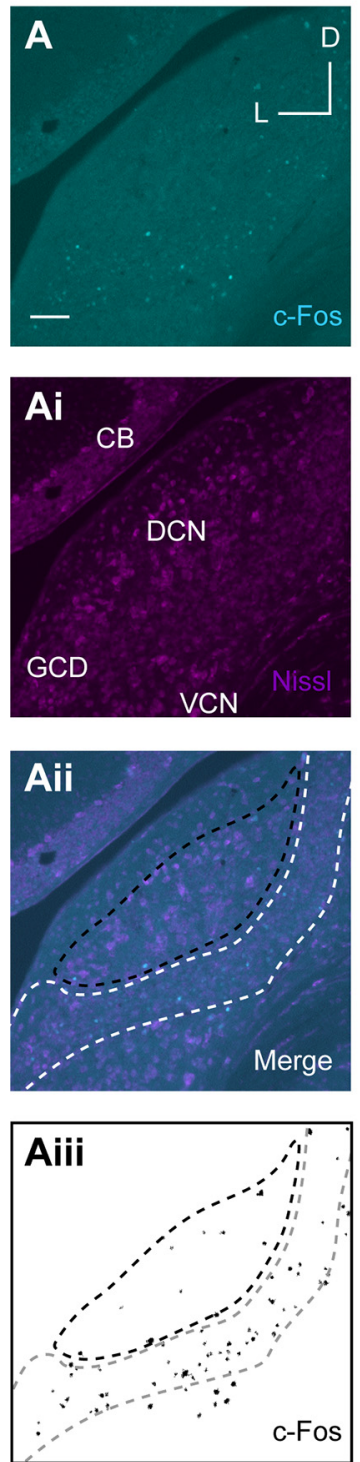

Positive control Vglut $3^{\text {tht }}$
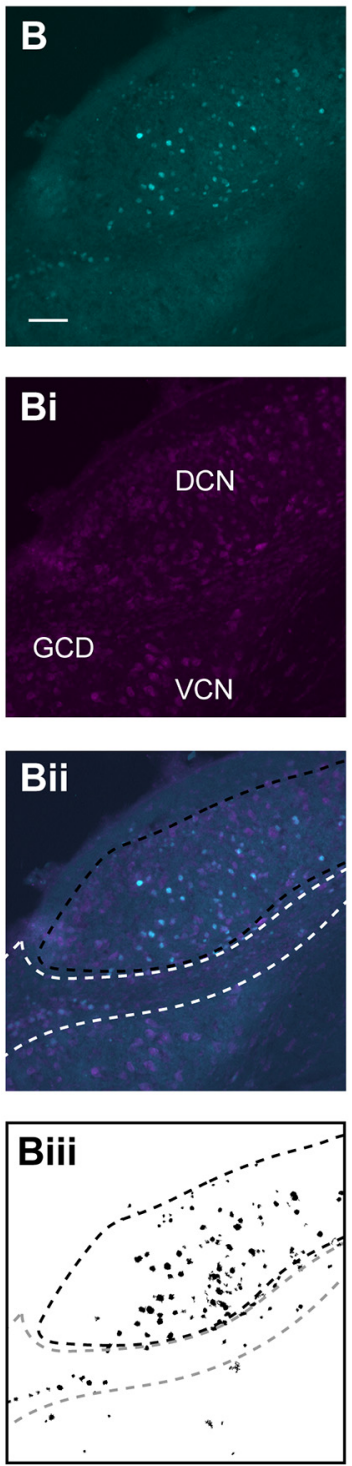

Negative control

Prestin CreERT2

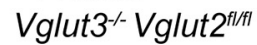
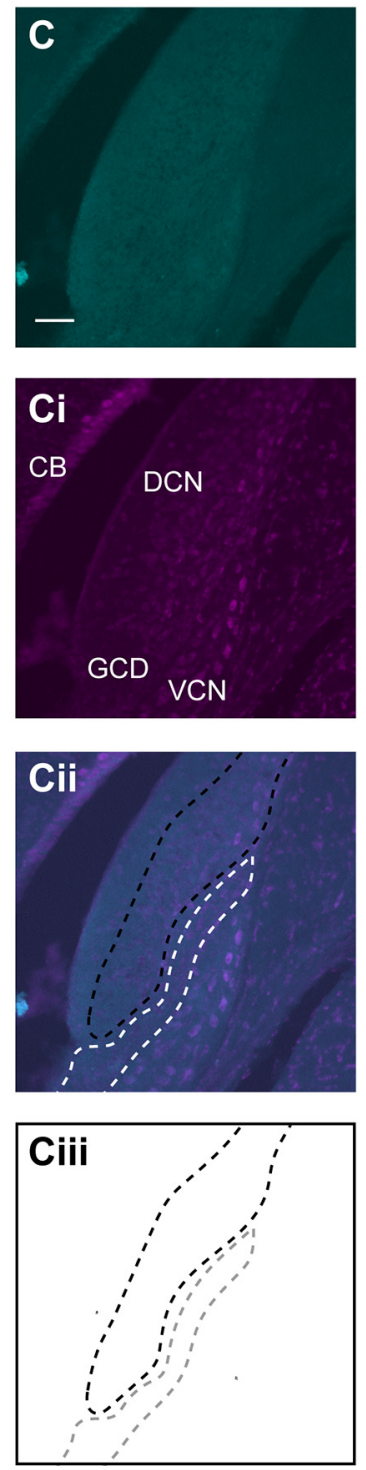

Vglut3 $^{\text {Cre }}$ Vglut ${ }^{f / f t l}$
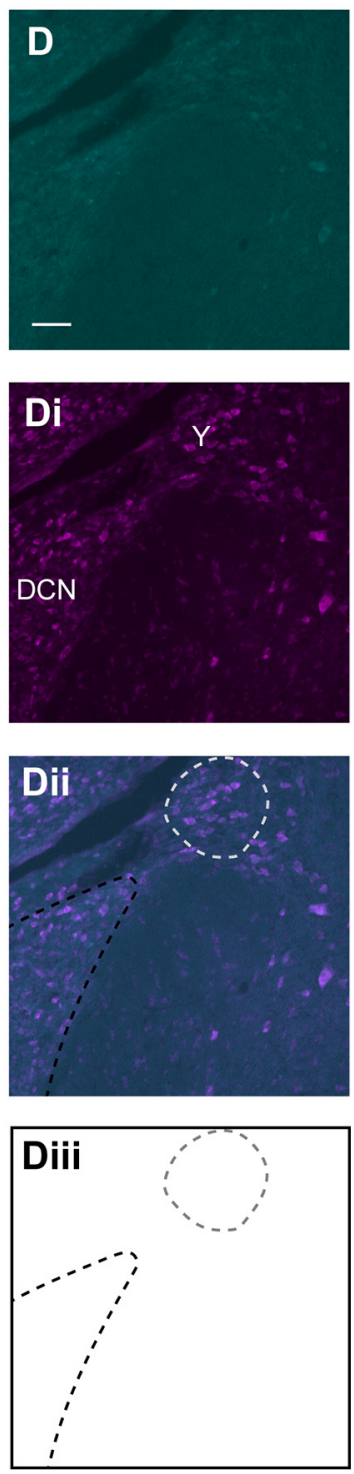

Figure 6. Sound-induced expression of c-Fos in the CN in response to an intense, $115 \mathrm{~dB}$ SPL, sound level. $\boldsymbol{A}$, Representative image from Vglut $3^{\text {Cre }}$ Vglut $3^{\mathrm{fl} / \mathrm{fl}}$ mouse after sound exposure shows C-Fos immunoreactivity (cyan) restricted to the GCD. Ai, Nissl staining (magenta). Aii, Merge of cyan and magenta channels. CB, Cerebellum. Aiii, Mask of c-Fos signal from A. Aii-Cii, Region enclosed by white dashed line indicates GCD. Region enclosed by black dashed line indicates regions of the DCN that also contain granule cells. Aiii-Ciii, Region enclosed by gray dashed line indicates GCD. Region enclosed by black dashed line indicates regions of the DCN that also contain granule cells. B, Representative image of CN from Vglut $3^{\mathrm{fl} / \mathrm{fl}}$ (positive control) after sound exposure shows C-Fos immunoreactivity (cyan) throughout DCN and GCD. Bi, Nissl staining of cell somata (magenta). Bii, Merge of cyan and magenta channels. Biii, Mask of c-Fos signal from

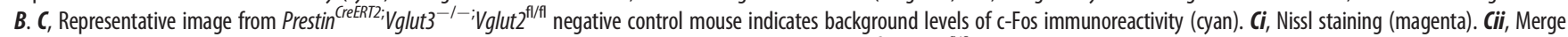
of cyan and magenta channels. Ciii, Mask of C-Fos signal from C. D, Representative image from Vglut $3^{\text {(re) }}$ Vglut $3^{\text {fl/ffl }}$ after sound exposure shows a lack of c-Fos immunoreactivity (cyan) in Nucleus Y (Y). Di, Nissl staining (magenta). Y, Nucleus Y. Dii, Merge of cyan and magenta channels. Region enclosed by black dashed line indicates regions of the DCN. Region enclosed by gray dashed line indicates Nucleus Y. Diii, Mask of c-Fos signal from D. Region enclosed by black dashed line indicates regions of the DCN. Region enclosed by gray dashed line indicates Nucleus Y. Scale bar, $100 \mu \mathrm{m}$.

\section{Discussion}

In this study, we demonstrate that glutamate release by OHCs is predominantly mediated by VGluT3 at P8. We generated novel mouse models to then show that a fundamental yet understudied glutamatergic pathway of the auditory system (OHC-Type II SGN pathway) activates $\mathrm{CN}$ neurons in response to moderate levels of sound. This result is contrary to earlier predictions based on the anatomic and physiological properties of OHCType II SGN signaling, which suggested that activation of central neurons would require loud sound (Robertson, 1984;
Simmons and Liberman, 1988b; Brown, 1994; Weisz et al., 2009; Liu et al., 2015).

Compared with IHCs, OHCs show a low probability of vesicle release at least in vitro (Weisz et al., 2012); thus, the presence of two VGluTs to support sparse vesicular release was unexpected. Nevertheless, VGluT3 KO mice showed a marked reduction in the frequency of PSCs in Type II SG afferents, suggesting a predominant role for this isoform in $\mathrm{OHC}$ glutamate release.

Measurements of the ABR thresholds of $\mathrm{Vglut}^{+/+}$mice subjected to $80 \mathrm{~dB}$ SPL white noise were unchanged, indicating that 
A

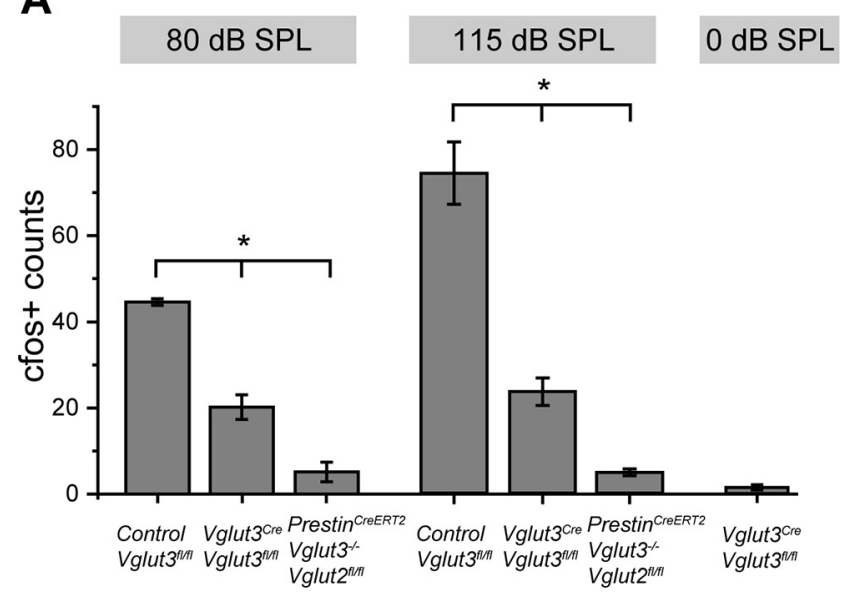

B

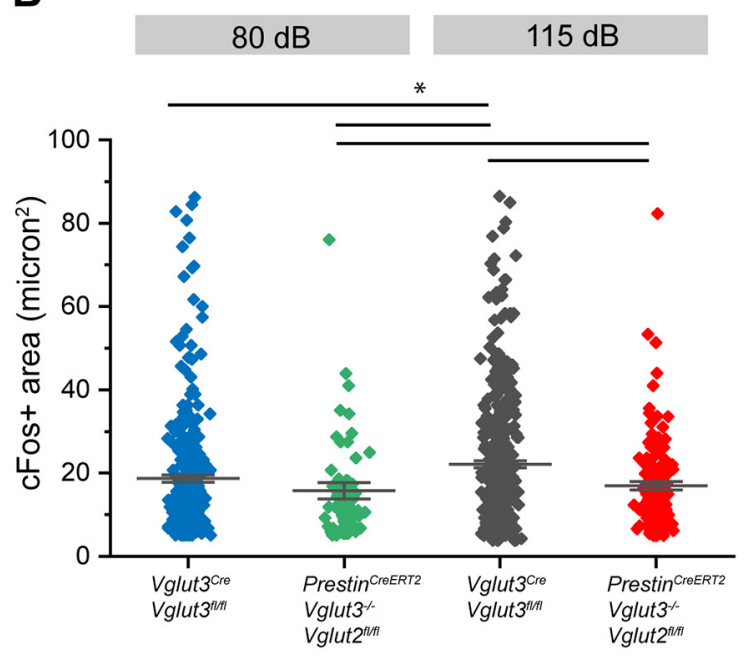

C

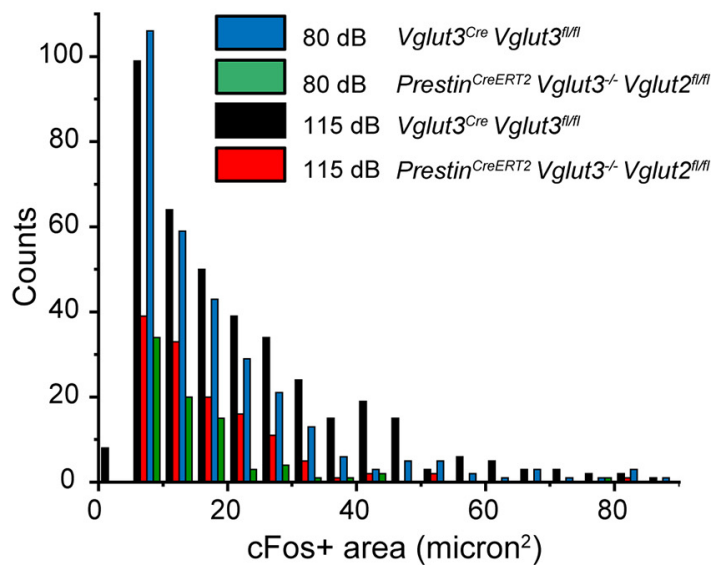

Figure 7. Analysis of $\mathrm{c}^{-} \mathrm{FoS}^{+}$neurons in the $\mathrm{CN}$ in response to sound. $\boldsymbol{A}$, Quantification of

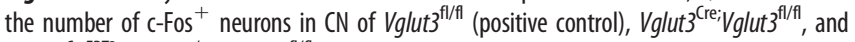
Prestin $^{\text {CreERT2i }}$ Vglut $^{-1-;}$ Vglut2 $^{\text {fl/fl }}$ (negative control) mice following 80, 115, or $0 \mathrm{~dB}$ SPL

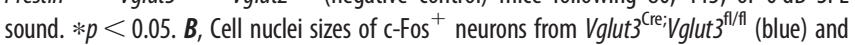
Prestin ${ }^{\text {CreERT2 }}$ Vglut ${ }^{-1-i} V_{\text {glut2 }}{ }^{\mathrm{fl} / \mathrm{fl}}$ (green) mice exposed to $80 \mathrm{~dB}$ SPL sound, and from

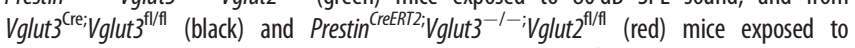
$115 \mathrm{~dB}$ SPL sound. $* p<0.05$. C, Frequency histogram of $c$-Fos ${ }^{+}$cell nuclei sizes shown in B. $n=5-7$ mice per genotype. cochlear function remains normal after this moderate sound level exposure. In contrast, the thresholds measured following $115 \mathrm{~dB}$ SPL exposure were significantly increased but with no obvious loss of hair cells or stereocilia. The lack of damage in our experiment could be because of differences in noise exposure parameters or in genetic background (Yoshida et al., 2000; Liberman and Kujawa, 2017). Nevertheless, here we show that cFos induction in the $\mathrm{CN}$ following this intense stimulus was dependent on OHC glutamate signaling, suggesting that synaptic vesicle release by OHCs was also still intact. These data differ from a related study by Flores et al. (2015), in which cFos induction was measured in the CN of global VGluT3 KO mice. In that study, in contrast to the current study, OHCs were completely lost with the loud sound induction paradigm (Flores et al., 2015). In light of this, the Flores et al. (2015) study more likely examines the activation of Type II SG afferents by nonregulated glutamate release, ATP, UTP, or other signaling molecules released from damaged cochlear cells (Gale et al., 2004; Liu et al., 2015).

Interestingly, ATP is also released into the endolymphatic compartment and cochlear partition in response to lower sound pressure levels (Muñoz et al., 2001; Housley et al., 2013). However, if purinergic signaling served as the main contributor to c-Fos induction in the $\mathrm{CN}$ after moderate sound exposure, it would have been expected to occur in all genotypes equally. Rather, the mouse lines we developed for this study have allowed us to precisely control glutamate release from IHCs and OHCs, and thus to attribute the resulting changes in $\mathrm{CN}$ c-Fos to sound-evoked release of vesicular glutamate by OHCs onto Type II SGNs. We tested only broadband sound stimuli. Given the convergent anatomic arrangement of OHCs onto the Type II SG afferents, it would be interesting to test whether pure tones delivered at $80 \mathrm{~dB}$ SPL are capable of evoking sufficient OHC glutamate- mediated input to activate the Type II SGN and, subsequently, neurons in the GCD of the CN.

The $\mathrm{CN}$ neurons that upregulated c-Fos in our study are likely to be monosynaptically connected to Type II SGN, but potentially also could be polysynaptically connected. In either case, the findings reported here are consistent with anatomic work suggesting that cells of the GCD constitute the majority of the targets of Type II SG afferents in the CN (Berglund et al., 1996; Benson and Brown, 2004). Cells in the GCD that expressed c-Fos in response to sound-induced activation of the OHC-Type II pathway varied in size, with a majority having nuclear areas of $<30 \mu \mathrm{m}^{2}$. It is likely that many of these cells are granule cells, which are the most abundant cell type in this domain. Granule cells are excitatory neurons that form parallel fibers that synapse onto fusiform, stellate, and cartwheel cells in the superficial layers of the DCN (Manis and Molitor, 1996; Rubio and Wenthold, 1997), and are thought to modulate sensitivity to auditory and nonauditory input (Oertel and Young, 2004). Other proposed targets that showed c-Fos expression included granule cells that reside in the DCN fusiform and deep layers, (Ryugo et al., 2003). It is possible that some of the c-Fos ${ }^{+}$cells in the GCD of both the Vglut $3^{\mathrm{Cre}} ; \mathrm{Vglut}^{f^{l / f l}}$ and the negative control: Prestin $^{\text {Cre }} ;$ Vglut $^{-1-} ;$ Vglut $^{\mathrm{fl} / \mathrm{fl}}$ mice may have been induced by the activation of additional pathways that feed into the GCD, such as the medial olivo-CN, cuneo-CN, spinal trigeminal nucleus, VCN, lateral reticular nucleus, periaqueductal gray, pontine nucleus, raphe nuclei, vestibular nucleus, vestibular and C2 DRG afferents, and Roller's nucleus (Kromer and Moore, 1980; Itoh et al., 1987; Burian and Gstoettner, 1988; Pedemonte et al., 
1990; Ryan et al., 1990; Klepper and Herbert, 1991; Wright and Ryugo, 1996; Ohlrogge et al., 2001; Benson and Brown, 2004; Haenggeli et al., 2005; Zhan et al., 2006; Zhan and Ryugo, 2007). Vestibular afferent neurons originating in the saccule are soundresponsive (McCue and Guinan, 1994; Curthoys, 2017) and may also project to the CN GCD (Burian and Gstoettner, 1988; Kevetter and Perachio, 1989). We cannot rule out entirely that saccular afferents generate the $\mathrm{c}^{-\mathrm{Fos}^{+}}$signal in the GCD of Vglut $3^{\mathrm{Cre}} ;$ Vglut $3^{\mathrm{f} / \mathrm{fl}}$ mice, but we think that this is highly unlikely because saccular afferents respond to lower sound frequencies $(0.1 \mathrm{~Hz}$ to $3 \mathrm{kHz}$, with best activation $\sim 0.1-0.8 \mathrm{~Hz})$ than what was used for sound exposure in this work (McCue and Guinan, 1994; Curthoys, 2017); and Nucleus Y, a target of saccular afferents (Frederickson and Trune, 1986), exhibited very few c-Fos ${ }^{+}$ nuclei in the sections in which it was visible, and this did not differ between genotypes.

Last, the distribution of $\mathrm{c}-\mathrm{Fos}^{+}$neurons observed in the GCD of the negative control (Prestin ${ }^{\text {CreERT2 }} ; V_{\text {glut }}{ }^{-/-} ; V_{\text {glut }} 2^{\mathrm{fl} / \mathrm{fl}}$ ) mice exposed to sound were similar to Vglut $3^{\mathrm{Cre}} ; \mathrm{Vglut} 3^{\mathrm{fl} / \mathrm{fl}}$ mice not exposed to sound. This finding argues against c-Fos induction by sound-related processes in the negative control mice. It should be noted that c-Fos labeling was rarely detected in magnocellular regions of the DCN or VCN, the main targets of Type I SGN. However, c-Fos induction in neurons in the VCN was detected in only limited regions in WT mice, and not in central regions known to be densely innervated by Type I SGN, suggesting that an alternative method is necessary to assess Type I SGN activity. Nevertheless, the paucity of c-Fos staining does not rule out the potential for Type II SGNs to project to these regions. Interestingly, there was no increase in the number of $\mathrm{c}^{-F o s}{ }^{+}$ neurons in the GCD of $V$ glut $3^{\text {Cre }}$; Vglut $3^{\text {flffl }}$ mice at $115 \mathrm{~dB}$ SPL compared with $80 \mathrm{~dB}$ SPL consistent with the idea that c-Fos induction within neurons in the GCD is saturated within this $\mathrm{dB}$ range (Yang et al, 2005). Thus, type II SGNs are maximally activated at $80 \mathrm{~dB}$ SPL, or, more likely, it reflects the fact that c-Fos expression is simply a binary indicator of OHC-Type II SGN pathway activity, not an indicator of the degree of activation by sound of different intensities.

With this work, we have developed mouse lines that allow precise isolation of glutamate release to cochlear IHCs or OHCs. Using the new mouse lines, we have demonstrated pathwayspecific activation of $\mathrm{CN}$ neurons in response to moderate sound and, thus, that vesicular glutamate signaling by $\mathrm{OHCs}$ to Type II SGN may participate in acoustic perception at nontraumatic levels of sound. While this work does not elucidate a precise role of Type II SG neurons in hearing, it is consistent with convergence of the OHC-Type II pathway with both medial olivocochlear axon collaterals and multisensory descending projections in the GCD. The broad range of CN cell sizes activated by the OHC-Type II SGN pathway in this study also suggests diverse influences on $\mathrm{CN}$ computations.

\section{References}

Akil O, Chang J, Hiel H, Kong JH, Yi E, Glowatzki E, Lustig LR (2006) Progressive deafness and altered cochlear innervation in knock-out mice lacking prosaposin. J Neurosci 26:13076-13088.

Akil O, Seal RP, Burke K, Wang C, Alemi A, During M, Edwards RH, Lustig LR (2012) Article restoration of hearing in the VGluT3 knockout mouse using virally mediated gene therapy. Neuron 75:283-293.

Barker M, Solinski HJ, Hashimoto H, Tagoe T, Pilati N, Hamann M (2012) Acoustic overexposure increases the expression of VGluT-2 mediated projections from the lateral vestibular nucleus to the dorsal cochlear nucleus. PLoS One 7:e35955.
Benson TE, Brown MC (2004) Postsynaptic targets of Type II auditory nerve fibers in the cochlear nucleus. J Assoc Res Otolaryngol 5:111-125.

Berglund AM, Ryugo DK (1987) Hair cell innervation by spiral ganglion neurons in the mouse. J Comp Neurol 255:560-570.

Berglund AM, Benson TE, Brown MC (1996) Synapses from labeled Type II axons in the mouse cochlear nucleus. Hear Res 94:31-46.

Borgius L, Restrepo CE, Leao RN, Saleh N, Kiehn O (2010) A transgenic mouse line for molecular genetic analysis of excitatory glutamatergic neurons. Mol Cell Neurosci 45:245-257.

Brown MC (1987) Morphology of labeled afferent fibers in the guinea pig cochlea. J Comp Neurol 260:591-604.

Brown MC (1994) Antidromic responses of single units from the spiral ganglion. J Neurophysiol 71:1835-1847.

Brown MC, Ledwith JV (1990) Projections of thin (Type II) and thick (Type I) auditory-nerve fibers into the cochlear nucleus of the mouse. Hear Res 49:105-118.

Brown MC, Berglund AM, Kiang NY, Ryugo DK (1988) Central trajectories of Type II spiral ganglion neurons. J Comp Neurol 278:581-590.

Brownell WE, Bader CR, Bertrand D, de Ribaupierre Y (1985) Evoked mechanical responses of isolated cochlear outer hair cells. Science 227:194196.

Burian M, Gstoettner W (1988) Projection of primary vestibular afferent fibres to the cochlear nucleus in the guinea pig. Neurosci Lett 84:1317.

Cheng L, Duan B, Huang T, Zhang Y, Chen Y, Britz O, Garcia-Campmany L, Ren X, Vong L, Lowell BB, Goulding M, Wang Y, Ma Q (2017) Identification of spinal circuits involved in touch-evoked dynamic mechanical pain. Nat Neurosci 20:804-814.

Clarkson C, Antunes FM, Rubio ME (2016) Conductive hearing loss has long-lasting structural and molecular effects on presynaptic and postsynaptic structures of auditory nerve synapses in the cochlear nucleus. J Neurosci 36:10214-10227.

Curthoys IS (2017) The new vestibular stimuli: sound and vibration-anatomical, physiological and clinical evidence. Exp Brain Res 235:957972.

Dannhof BJ, Bruns V (1993) The innervation of the organ of Corti in the rat. Hear Res 66:8-22.

Davis KA, Young ED (1997) Granule cell activation of complex-spiking neurons in dorsal cochlear nucleus. J Neurosci 17:6798-6806.

Divito CB, Steece-Collier K, Case DT, Williams SG, Stancati JA, Zhi L, Rubio ME, Sortwell XC, Collier TJ, Sulzer D, Edwards RH, Zhang H, Seal RP (2015) Loss of VGluT3 produces circadian-dependent hyperdopaminergia and ameliorates motor dysfunction and L-Dopa-mediated dyskinesias in a model of Parkinson's disease. J Neurosci 35: 14983-14999.

Dunn R, Morest D (1975) Receptor synapses without synaptic ribbons in the cochlea of the cat. Proc Natl Acad Sci USA 72:3599-3603.

Echteler SM (1992) Developmental segregation in the afferent projections to mammalian auditory hair cells. Proc Natl Acad Sci USA 89:6324-6327.

Evans BN, Dallos P (1993) Stereocilia displacement induced somatic motility of cochlear outer hair cells. Proc Natl Acad Sci USA 90:8347-8351.

Fang J, Zhang WC, Yamashita T, Gao J, Zhu MS, Zuo J (2012) Outer hair cell-specific prestin-CreERT2 knockin mouse lines. Genesis 50:124131.

Fekete DM, Rouiller EM, Liberman MC, Ryugo DK (1984) The central projections of intracellularly labeled auditory nerve fibers in cats. J Comp Neurol 229:432-450.

Flores EN, Duggan A, Madathany T, Hogan AK, Márquez FG, Kumar G, Seal RP, Edwards RH, Liberman MC, García-Añoveros J (2015) A noncanonical pathway from cochlea to brain signals tissue-damaging noise. Curr Biol 25:1-7.

Floris A, Diño M, Jacobowitz DM, Mugnaini E (1994) The unipolar brush cells of the rat cerebellar cortex and cochlear nucleus are calretinin-positive: a study by light and electron microscopic immunocytochemistry. Anat Embryol (Berl) 189:495-520.

Frederickson CJ, Trune DR (1986) Cytoarchitecture and saccular innervation of nucleus $Y$ in the mouse. J Comp Neurol 252:302-322.

Gale JE, Piazza V, Ciubotaru CD, Mammano F (2004) A mechanism for sensing noise damage in the inner ear. Curr Biol 14:526-529.

Ginzberg RD, Morest DK (1983) A study of cochlear innervation in the young cat with the Golgi method. Hear Res 10:227-246. 
Ginzberg RD, Morest DK (1984) Fine structure of cochlear innervation in the cat. Hear Res 14:109-127.

Glowatzki E, Fuchs PA (2002) Transmitter release at the hair cell ribbon synapse. Nat Neurosci 5:147-154.

Grimes WN, Seal RP, Oesch N, Edwards RH, Diamond JS (2011) Genetic targeting and physiological features of $\mathrm{VGluT}^{+}$amacrine cells. Vis Neurosci 28:381-392.

Haenggeli CA, Pongstaporn T, Doucet JR, Ryugo DK (2005) Projections from the spinal trigeminal nucleus to the cochlear nucleus in the rat. $\mathrm{J}$ Comp Neurol 484:191-205.

Hafidi A (1998) Peripherin-like immunoreactivity in Type II spiral ganglion cell body and projections. Brain Res 805:181-190.

Harris JA, Hirokawa KE, Sorensen SA, Gu H, Mills M, Ng LL, Bohn P, Mortrud M, Ouellette B, Kidney J, Smith KA, Dang C, Sunkin S, Bernard A, Oh SW, Madisen L, Zeng H (2014) Anatomical characterization of Cre driver mice for neural circuit mapping and manipulation. Front Neural Circuits 8:1-16.

Housley GD, Morton-Jones R, Vlajkovic SM, Telang RS, Paramananthasivam V, Tadros SF, Wong AC, Froud KE, Cederholm JM, Sivakumaran Y, Snguanwongchai P, Khakh BS, Cockayne DA, Thorne PR, Ryan AF (2013) ATP-gated ion channels mediate adaptation to elevated sound levels. Proc Natl Acad Sci USA 110:7494-7499.

Hurd LB, Hutson KA, Morest DK (1999) Cochlear nerve projections to the small cell shell of the cochlear nucleus: the neuroanatomy of extremely thin sensory axons. Synapse 33:83-117.

Itoh K, Kamiya H, Mitani A, Yasui Y, Takada M, Mizuno N (1987) Direct projections from the dorsal column nuclei and the spinal trigeminal nuclei to the cochlear nuclei in the cat. Brain Res 400:145-150.

Kanold PO, Young ED (2001) Proprioceptive information from the pinna provides somatosensory input to cat dorsal cochlear nucleus. J Neurosci 21:7848-7858

Kevetter GA, Perachio AA (1989) Projections from the sacculus to the cochlear nuclei in the Mongolian gerbil. Brain Behav Evol 34:193-200.

Kiang NY, Rho JM, Northrop CC, Liberman MC, Ryugo DK (1982) Hair-cell innervation by spiral ganglion cells in adult cats. Science 217:175-177.

Kim KX, Payne S, Yang-Hood A, Li SZ, Davis B, Carlquist J, V-Ghaffari B, Gantz JA, Kallogjeri D, Fitzpatrick JA, Ohlemiller KK, Hirose K, Rutherford MA (2019) Vesicular glutamatergic transmission in noiseinduced loss and repair of cochlear ribbon synapses. J Neurosci 39:44344447.

Klepper A, Herbert H (1991) Distribution and origin of noradrenergic and serotonergic fibers in the cochlear nucleus and inferior colliculus of the rat. Brain Res 557:190-201.

Koundakjian E, Appler J, Goodrich L (2007) Auditory neurons make stereotyped wiring decisions before maturation of their targets. J Neurosci 27:14078-14088.

Kromer LF, Moore RY (1980) Norepinephrine innervation of the cochlear nuclei by locus coeruleus neurons in the rat. Anat Embryol (Berl) 158:227-244.

Liberman MC, Dodds LW, Pierce S (1990) Afferent and efferent innervation of the cat cochlea: quantitative analysis with light and electron microscopy. J Comp Neurol 301:443-460.

Liberman MC, Kujawa SG (2017) Cochlear synaptopathy in acquired sensorineural hearing loss: manifestations and mechanisms. Hear Res 349:138147.

Liu C, Glowatzki E, Fuchs PA (2015) Unmyelinated Type II afferent neurons report cochlear damage. Proc Natl Acad Sci 112:14723-14727.

Madisen L, Mao T, Koch H, Zhuo JM, Berenyi A, Fujisawa S, Hsu YW, Garcia AJ, Gu X, Zanella S, Kidney J, Gu H, Mao Y, Hooks BM, Boyden ES, Buzsáki G, Ramirez JM, Jones AR, Svoboda K, Han X, et al. (2012) A toolbox of Cre-dependent optogenetic transgenic mice for light-induced activation and silencing. Nat Neurosci 15:793-802.

Manis PB, Molitor SC (1996) N-methyl-D-aspartate receptors at parallel fiber synapses in the dorsal cochlear nucleus. J Neurophysiol 76: 1639-1656.

McCue MP, Guinan JJ (1994) Acoustically responsive fibers in the vestibular nerve of the cat. J Neurosci 14:6058-6070.

Morgan YV, Ryugo DK, Brown MC (1994) Central trajectories of Type II (thin) fibers of the auditory nerve in cats. Hear Res 79:74-82.

Mugnaini E, Osen KK, Dahl AL, Friedrich VL Jr, Korte G, Friedrich VL, Korte G (1980a) Fine structure of granule cells and related interneurons (termed Golgi cells) in the cochlear nuclear complex of cat, rat and mouse. J Neurocytol 9:537-570.

Mugnaini E, Warr WB, Osen KK (1980b) Distribution and light microscopic features of granule cells in the cochlear nuclei of cat, rat, and mouse. J Comp Neurol 191:581-606.

Muñoz DJ, Kendrick IS, Rassam M, Thorne PR (2001) Vesicular storage of adenosine triphosphate in the guinea-pig cochlear lateral wall and concentrations of ATP in the endolymph during sound exposure and hypoxia. Acta Otolaryngol 121:10-15.

Nouvian R, Beutner D, Parsons TD, Moser T (2006) Structure and function of the hair cell ribbon synapse. J Membr Biol 209:153-165.

Oertel D, Young ED (2004) What's a cerebellar circuit doing in the auditory system? Trends Neurosci 27:104-110.

Ohlrogge M, Doucet JR, Ryugo DK (2001) Projections of the pontine nuclei to the cochlear nucleus in rats. J Comp Neurol 436:290-303.

Pedemonte M, Pena JL Jr, Velluti R, Peña JL Jr (1990) Periaqueductal gray influence on anteroventral cochlear nucleus unitary activity and naloxone effects. Hear Res 47:219-227.

Peirs C, Williams SP, Zhao X, Walsh CE, Gedeon JY, Cagle NE, Goldring AC, Hioki H, Liu Z, Marell PS, Seal RP (2015) Dorsal horn circuits for persistent mechanical pain. Neuron 87:797-812.

Perkins RE, Morest DK (1975) A study of cochlear innervation patterns in cats and rats with the Golgi method and Nomarkski optics. J Comp Neurol 163:129-158.

Robertson D (1984) Horseradish peroxidase injection of physiologically characterized afferent and efferent neurones in the guinea pig spiral ganglion. Hear Res 15:113-121.

Robertson D, Sellick PM, Patuzzi R (1999) The continuing search for outer hair cell afferents in the guinea pig spiral ganglion. Hear Res 136:151158.

Rubio ME (2018) Microcircuits of the anteroventral cochlear nucleus. In: The mammalian auditory pathways: Springer handbook of auditory research, pp 41-71. New York: Springer.

Rubio ME, Wenthold RJ (1997) Glutamate receptors are selectively targeted to postsynaptic sites in neurons. Neuron 18:939-950.

Ruel J, Emery S, Nouvian R, Bersot T, Amilhon B, Van Rybroek JM, Rebillard G, Lenoir M, Eybalin M, Delprat B, Sivakumaran TA, Giros B, El Mestikawy S, Moser T, Smith RJH, Lesperance MM, Puel J-L (2008) Impairment of SLC17A8 encoding vesicular glutamate transporter-3, VGLUT3, underlies nonsyndromic deafness DFNA25 and inner hair cell dysfunction in null mice. Am J Hum Genet 83:278-292.

Ryan AF, Keithley EM, Wang ZX, Schwartz IR (1990) Collaterals from lateral and medial olivocochlear efferent neurons innervate different regions of the cochlear nucleus and adjacent brainstem. J Comp Neurol 300:572582 .

Ryugo DK, Dodds LW, Benson TE, Kiang NY (1991) Unmyelinated axons of the auditory nerve in cats. J Comp Neurol 308:209-223.

Ryugo DK, Haenggeli CA, Doucet JR (2003) Multimodal inputs to the granule cell domain of the cochlear nucleus. Exp Brain Res 153:477485.

Schmidt EF, Kus L, Gong S, Heintz N (2013) BAC transgenic mice and the GENSAT database of engineered mouse strains. Cold Spring Harb Protoc 2013:pdb.top073692.

Seal RP, Akil O, Yi E, Weber CM, Grant L, Yoo J, Clause A, Kandler K, Noebels JL, Glowatzki E, Lustig LR, Edwards RH (2008) Sensorineural deafness and seizures in mice lacking vesicular glutamate transporter 3 . Neuron 57:263-275.

Shore SE, Vass Z, Wys NL, Altschuler RA (2000) Trigeminal ganglion innervates the auditory brainstem. J Comp Neurol 419:271-285.

Simmons DD, Liberman MC (1988a) Afferent innervation of outer hair cells in adult cats: II. Electron microscopic analysis of fibers labeled with horseradish peroxidase. J Comp Neurol 270:145-154.

Simmons DD, Liberman MC (1988b) Afferent innervation of outer hair cells in adult cats: I. Light microscopic analysis of fibers labeled with horseradish peroxidase. J Comp Neurol 270:132-144.

Spoendlin H (1967) The innervation of the organ of Corti. J Laryngol Otol 81:717-738

Spoendlin H (1969) Innervation patterns in the organ of Corti of the cat. Acta Otolaryngol 67:239-254.

Tong Q, Ye CP, McCrimmon RJ, Dhillon H, Choi B, Kramer MD, Yu J, Yang Z, Christiansen LM, Lee CE, Choi CS, Zigman JM, Shulman GI, Sherwin RS, Elmquist JK, Lowell BB (2007) Synaptic glutamate release by 
ventromedial hypothalamic neurons is part of the neurocircuitry that prevents hypoglycemia. Cell Metab 5:383-393.

Vong L, Ye C, Yang Z, Choi B, Chua S, Lowell BB (2011) Leptin action on GABAergic neurons prevents obesity and reduces inhibitory tone to POMC neurons. Neuron 71:142-154.

Weedman DL, Pongstaporn T, Ryugo DK (1996) Ultrastructural study of the granule cell domain of the cochlear nucleus in rats: mossy fiber endings and their targets. J Comp Neurol 369:345-360.

Weinberg R, Rustioni A (1987) A cuneocochlear pathway in the rat. Neuroscience 20:209-219.

Weisz CJ, Glowatzki E, Fuchs PA (2009) The postsynaptic function of Type II cochlear afferents. Nature 461:1126-1129.

Weisz CJ, Lehar M, Hiel H, Glowatzki E, Fuchs PA (2012) Synaptic transfer from outer hair cells to Type II afferent fibers in the rat cochlea. J Neurosci 32:9528-9536.

Weisz CJ, Glowatzki E, Fuchs PA (2014) Excitability of Type II cochlear afferents. J Neurosci 34:2365-2373.
Wright DD, Ryugo DK (1996) Mossy fiber projections from the cuneate nucleus to the cochlear nucleus in the rat. J Comp Neurol 365:159-172.

Yang Y, Saint Marie RL, Oliver DL (2005) Granule cells in the cochlear nucleus sensitive to sound activation detected by Fos protein expression. Neuroscience 136:865-882.

Yoshida N, Hequembourg SJ, Atencio CA, Rosowski JJ, Liberman MC (2000) Acoustic injury in mice: $129 / \mathrm{SvEv}$ is exceptionally resistant to noise-induced hearing loss. Hear Res 141:97-106.

Young ED, Nelken I, Conley RA (1995) Somatosensory effects on neurons in dorsal cochlear nucleus. J Neurophysiol 73:743765.

Zhan X, Ryugo DK (2007) Projections of the lateral reticular nucleus to the cochlear nucleus in rats. J Comp Neurol 504:583-598.

Zhan X, Pongstaporn T, Ryugo DK (2006) Projections of the second cervical dorsal root ganglion to the cochlear nucleus in rats. J Comp Neurol 496:335-348. 